\title{
th. 115.5
}

\section{Inspection of High-Temperature Gas-Cooled Reactor Recycle Fuel}

\author{
W. H. Pechin \\ W. J. Lackey \\ J. D. Sease \\ W. P. Eathe. Iy
}




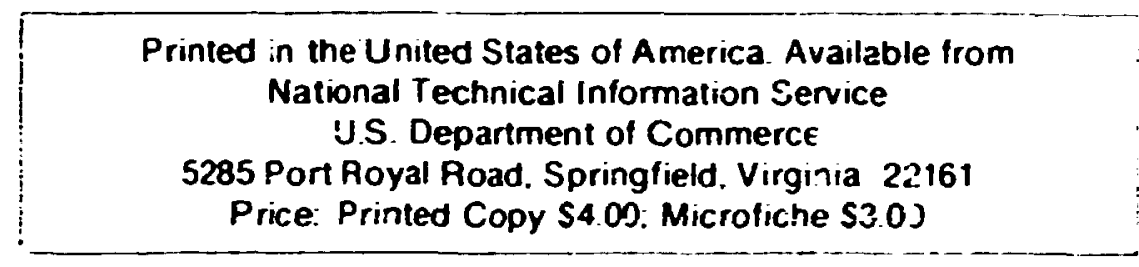

This repurt was prepared as ar. account of work sporisorit by the United States Government Neither the United Sidtes no: the Energy Research and Dovelopment Adminisiration United Siates Nuclear Regulatory Commiss:on. nor any of their employees. nor ary of theer contraclors sidbconiraciers. or their emplnyees makes zr.y warranty. express or implied or assumes any logallabirity or insocnsibility tor the accuracy. completeness or usefuness of any information. apporatis prodisct or process disclosed. or reprosents that its use woutd not infringe crivatelyowned r:ghts 
cetals and Cenamos divisoon

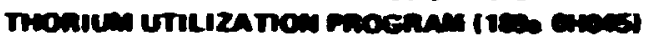

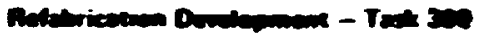

INSECTION OF MLHTEMTERATURE GASCOOLED REACTOR RECYCLE FUEL

W. H. Pechin, W. J. Lackey. J. D. Sexe, and W. P. Eatherly

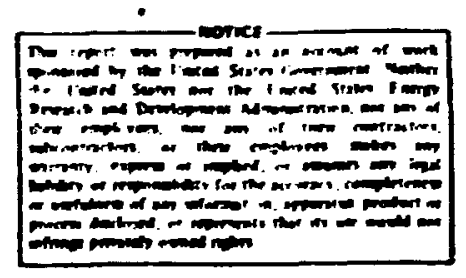
OAK RIDGE NATIONAL LABORATOAY Oak Pidge, Tennescee 37836 opereted by UNION CAABIDE CORPOAATION for the




\section{Coners}

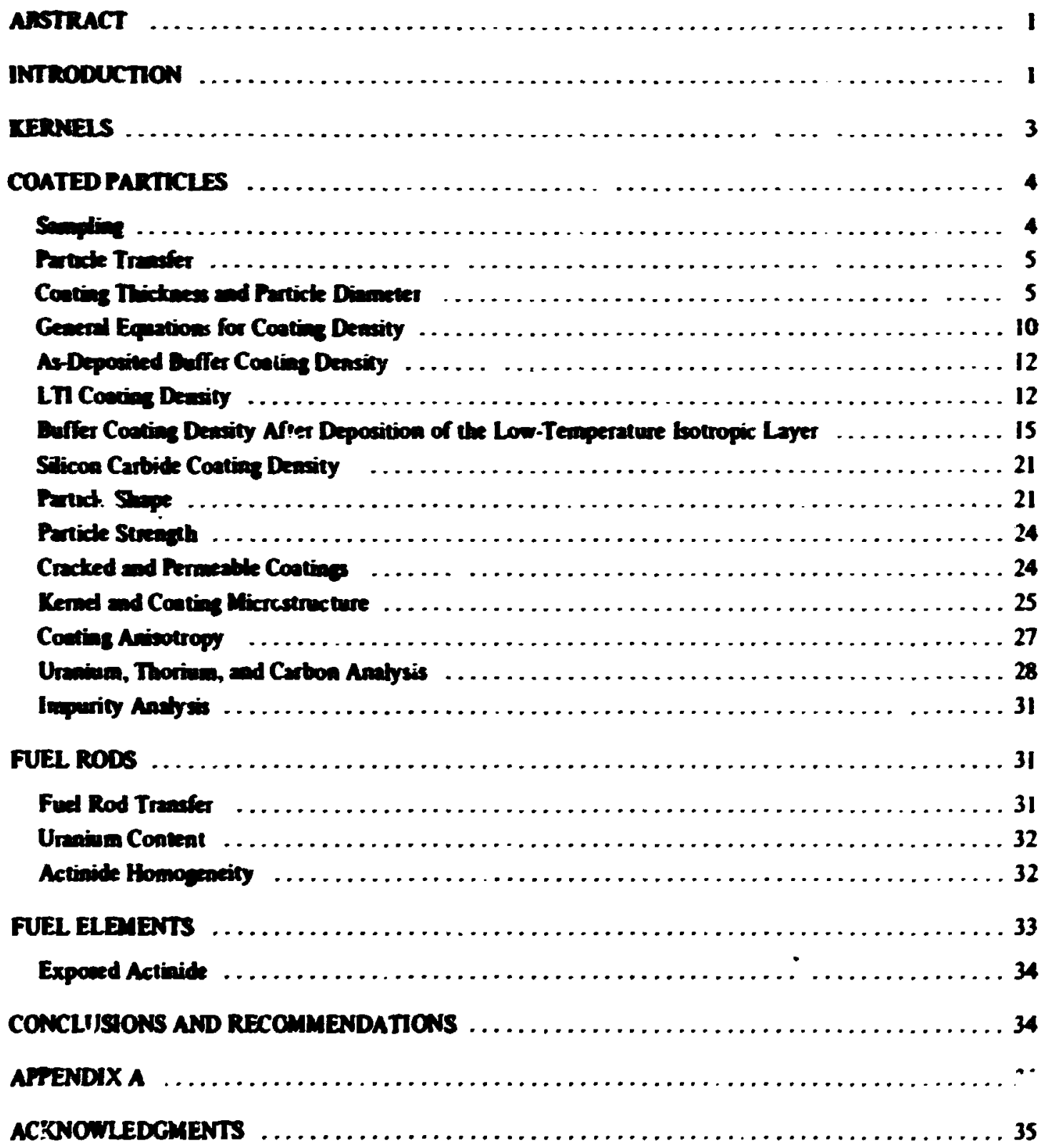




\title{
INSTECTION OF HIGH-TEMFERATURE GAS-COOLED REACTOR RECYCLE FUEL
}

\author{
W. H. Pechin, W. J. Lackey, J. D. Sease, and W. P. Eatherly
}

\begin{abstract}
ASTRACT

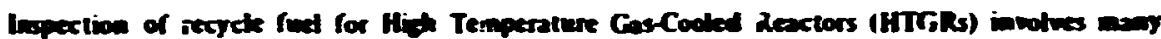

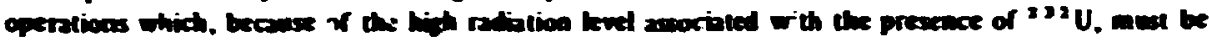

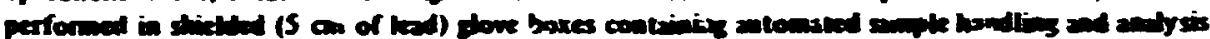

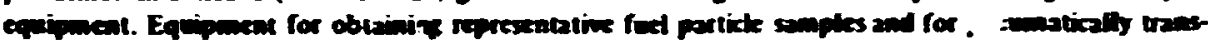

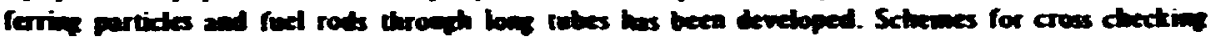

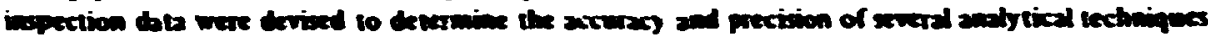

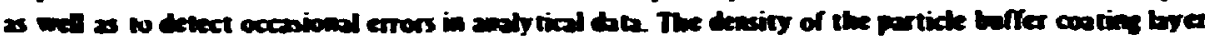

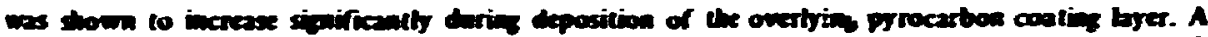

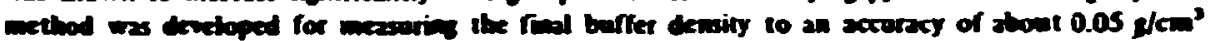

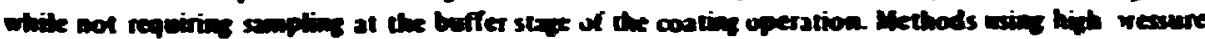

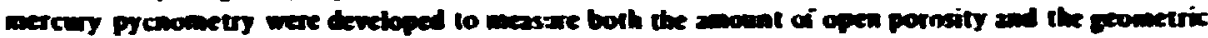

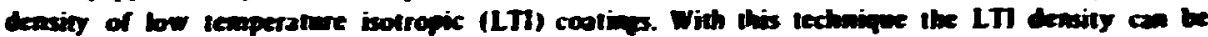

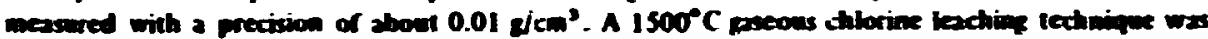

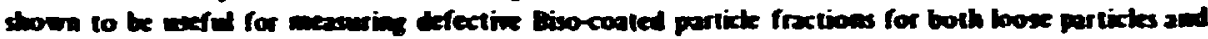

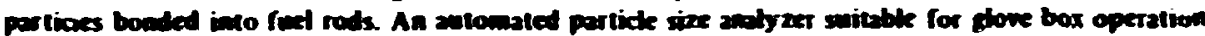

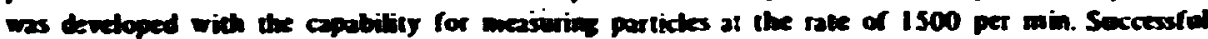
tachainges for mosuring perticle shepe and strength were abo developed.
\end{abstract}

\section{INTRODUCTION}

Fieh-Temperature Gas-Cooled Reactors' (HTGRs) have the potential for supplying process heat and, if fuel recycle capability is established, HTGRs wit provide improved fuel utilization when wed to produce etectricity. The HTGR fuel cycle begins with ${ }^{232} \mathrm{Th}$ and ${ }^{235} \mathrm{U}$. As a result of neutron capture and subsequent radicactive decay, some ${ }^{232} \mathrm{Th}$ is converted $10^{233} \mathrm{U}$. The fuel recyclinis process consists of separating the bred ${ }^{233} \mathrm{U}$ from the fission products and refabricating the ${ }^{233} \mathrm{U}$ into fuel. This paper describes the quality control tests required for the refabrication of HTGR fued.

Quality control cests for HTGR fuel have been under development for 15 years as part of the national HTGR recycle development program. ${ }^{2}$ The major objective of this program is the development of commercial fuel recycle technolozy. Recently. a conceptual design of a refabrication. pilot plant, including all required quality control functions, was completed.

The processing steps and product attributes (Fig. I) that must be controlled during refabrication of HTCR fuet my be grouped in four basic categories: preparation of fuel kernels, application of multiple layers of pyrolytic carbon and silicon carbide, preparation of fuel rods, and loading of fuel rods into holes in graphite fuel elcments.

Qusity control of refabricated HTGR fuel presents a unique problem because of the presence of some ${ }^{232} \mathrm{U}$, which is not removed by chemical processing. The highenergy gamma radiation from the radioactive decay of daughter products of ${ }^{232} \mathrm{U}$ requires that fabrication and quality control teating be performed in

1. H. B. Stewart. R. C. Dahloerg, W. V. Goeddel, D. B. Tracker, P. R. Kesten, and A. L Lotts. Ujulication of the

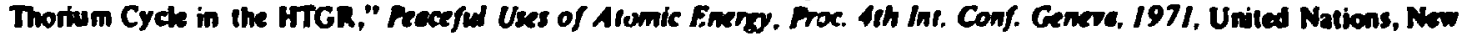
York, and International Atomic Enersy Agency, Vieana, 4: 433-47 1972).

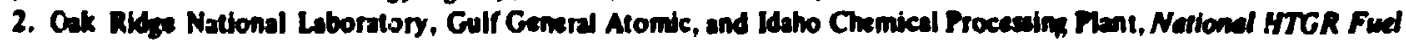
Recy de Drredopmemt Fin, ORNL-47M2, Rev. I (August 1973). 
Cont-ons 75-15usen

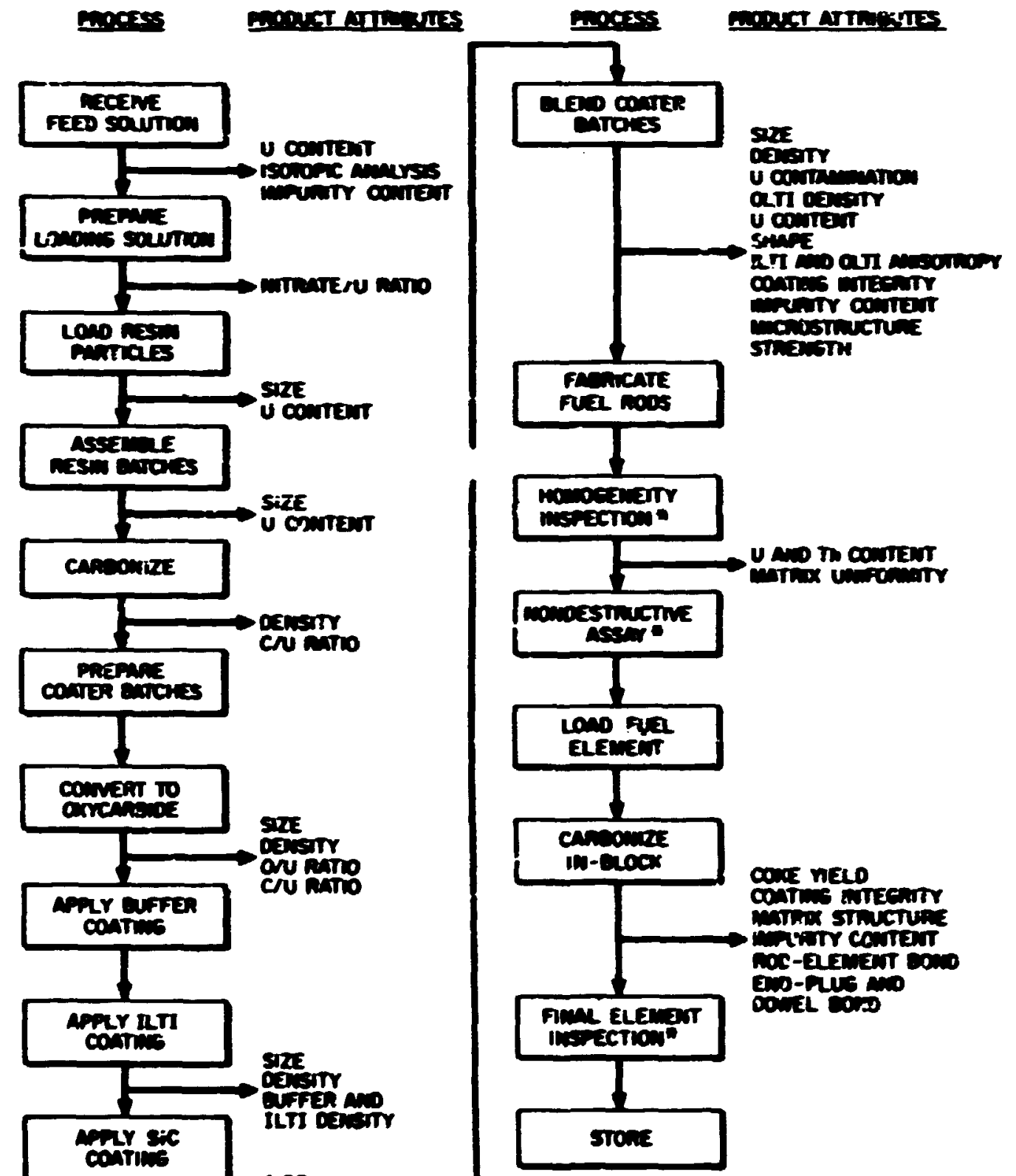

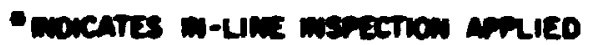
io roons or mopuct.

S12:

ocustr

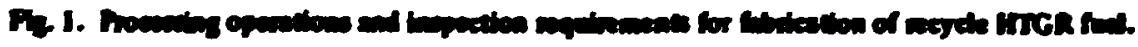




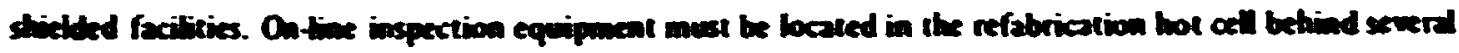

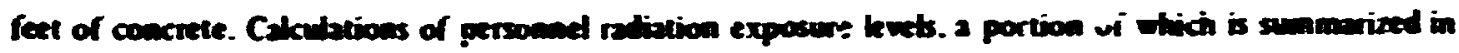

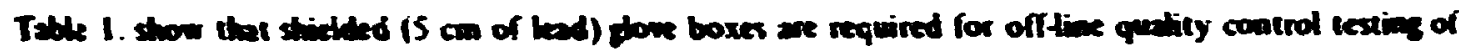

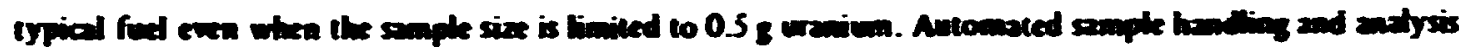

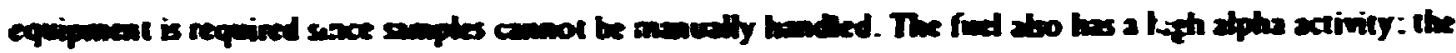

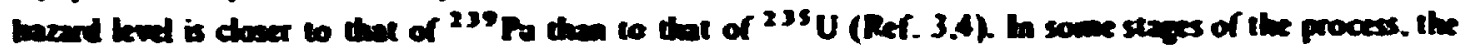

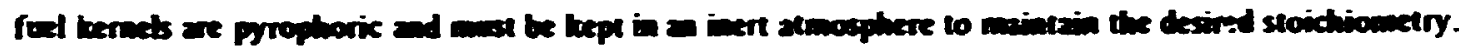

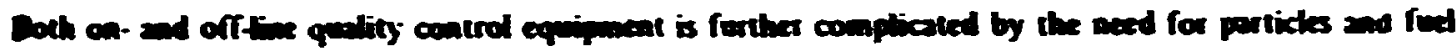
rods to be hodled remetely.

\section{renaves}

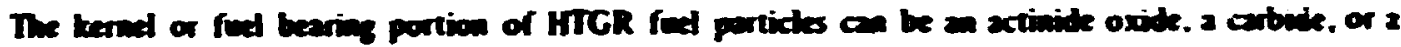

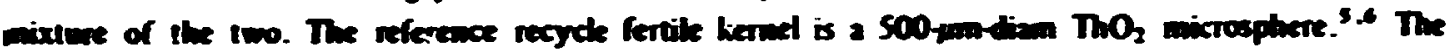

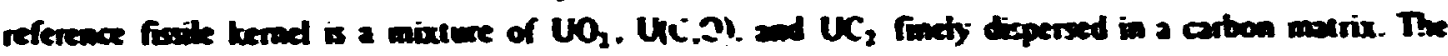

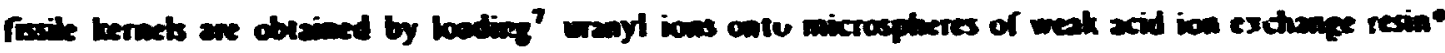

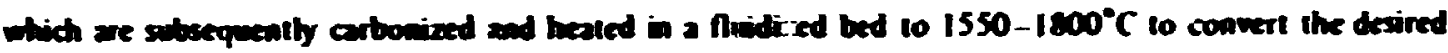

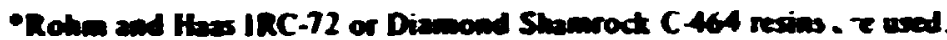

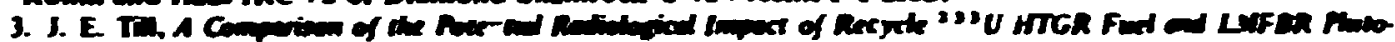

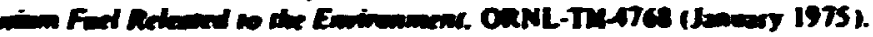

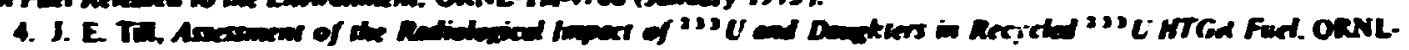

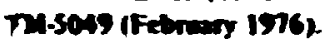

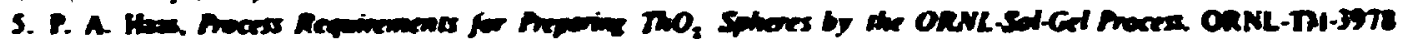
(Decesuler Is72)

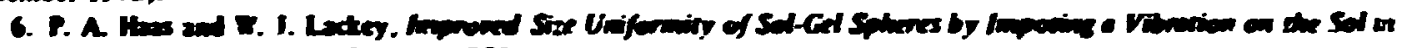

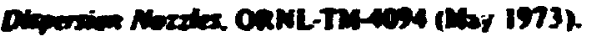

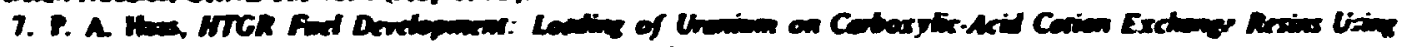

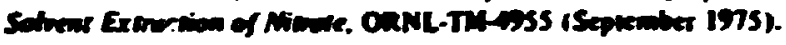

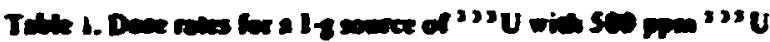

\begin{tabular}{|c|c|c|c|c|}
\hline \multirow{3}{*}{ 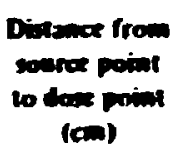 } & \multicolumn{4}{|c|}{ Dose rate (ascena/no) } \\
\hline & \multicolumn{4}{|c|}{ Dors since separation from is $\mathrm{U}$ dengter prodects } \\
\hline & 30 & 6 & so & 100 \\
\hline \multicolumn{5}{|c|}{ Whotwoed shivition } \\
\hline $\mathbf{1}$ & 2203 & 4.44 & 7.407 & 14.005 \\
\hline 2 & 551 & 1.112 & 1854 & 3.sss \\
\hline 5 & $\varepsilon .3$ & $1 \pi$ & 297 & ses \\
\hline 10 & 22.1 & 45 & 74.2 & 146 \\
\hline 29 & 552 & 11.1 & 18.6 & 36.6 \\
\hline 35 & 1.80 & 3.64 & 6.06 & 120 \\
\hline 50 & 0.88 & 1.78 & 2.97 & 5.26 \\
\hline 100 & 0.22 & 0.45 & 0.74 & 1.47 \\
\hline \multicolumn{5}{|c|}{ Thmos $5 \mathrm{~cm}$} \\
\hline 5.2 & 7.41 & 149 & 24.9 & 4.1 \\
\hline 10.0 & 2.00 & 4.04 & 6.73 & 13.3 \\
\hline 20.0 & 0.50 & 1.01 & 1.68 & 3.32 \\
\hline 350 & 0.164 & 0.33 & 0.55 & 1.08 \\
\hline$\$ 0.0$ & 0.000 & 0.162 & 0.27 & 0.53 \\
\hline
\end{tabular}




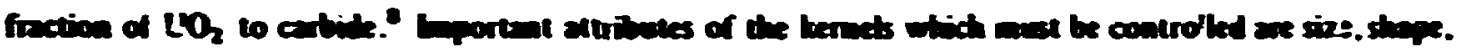

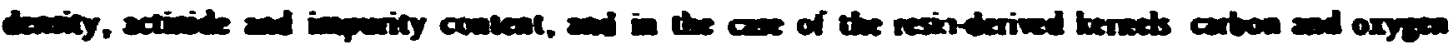

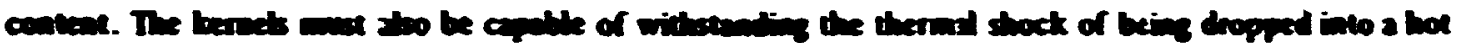

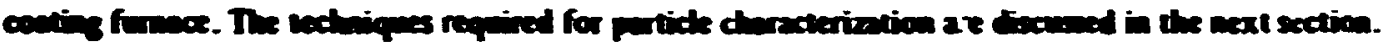

\section{COATED PARTCLES}



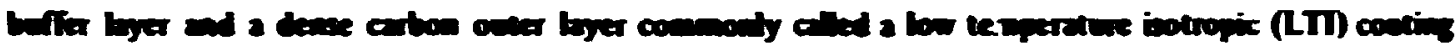

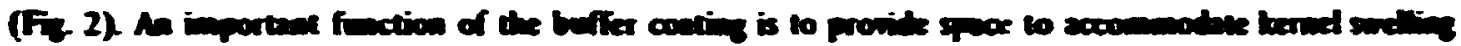

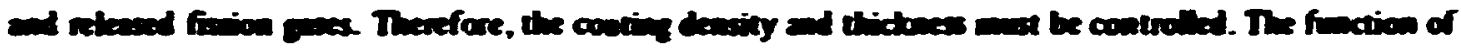

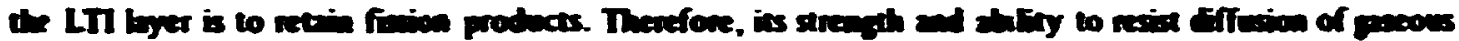

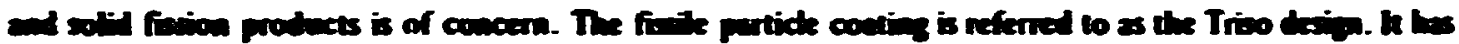

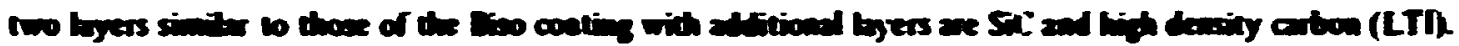

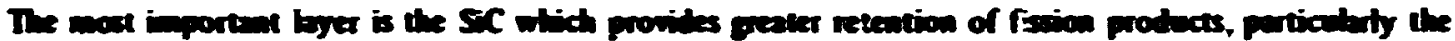

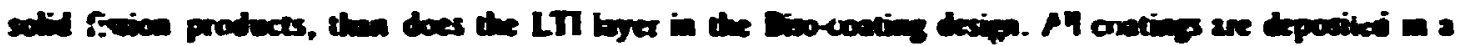

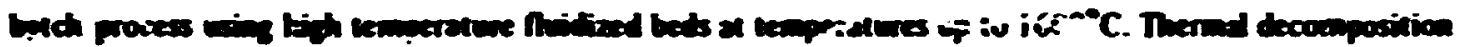

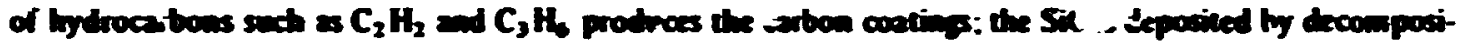
tion of $\mathrm{CH}_{3} \mathrm{C}_{3} \mathrm{si}$ in the presence of bydropen.

\section{sangers}

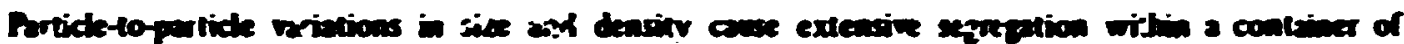

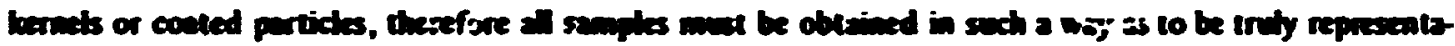

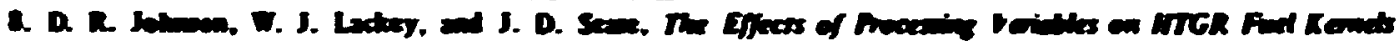

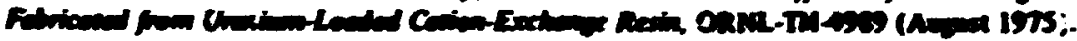

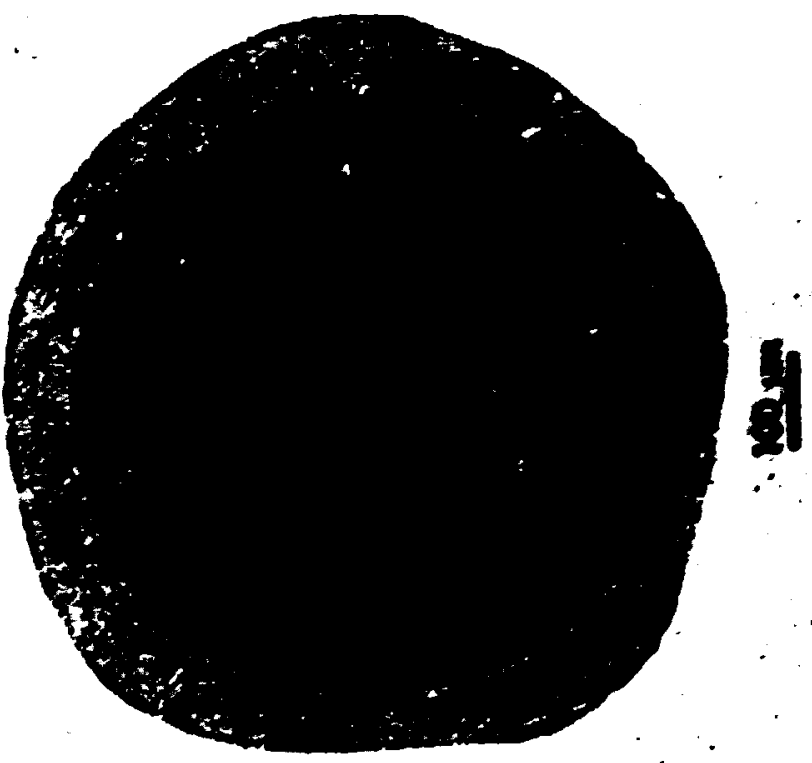

orso maz retre

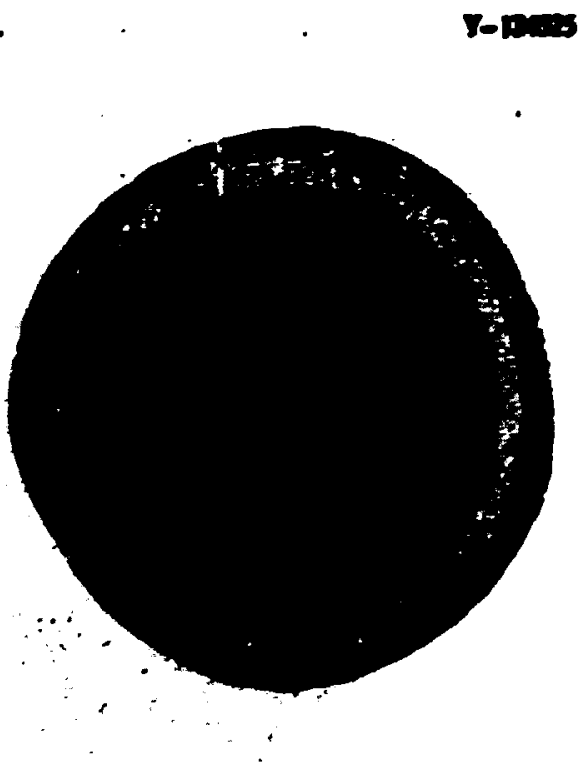

miso estin fissice

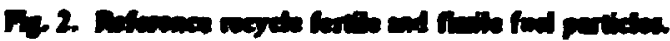




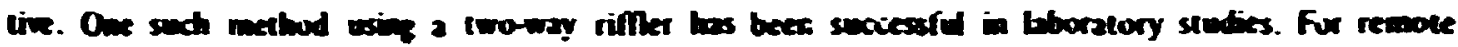

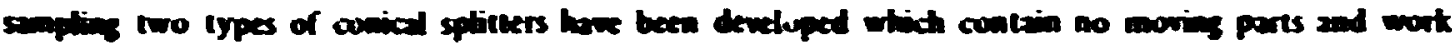

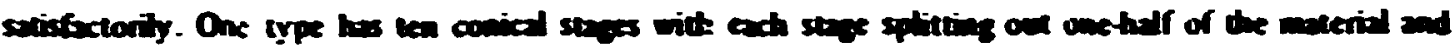

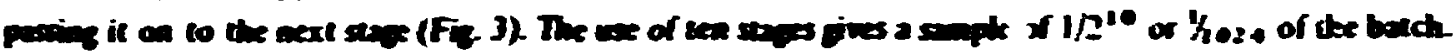

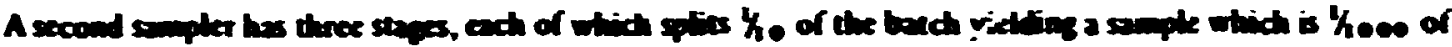

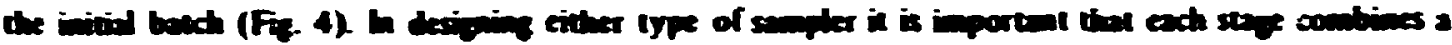

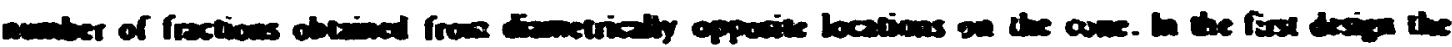

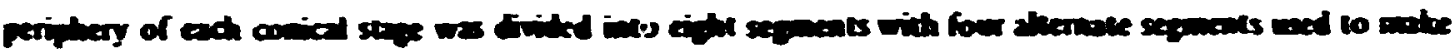

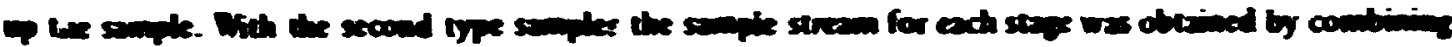

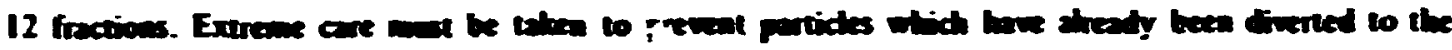

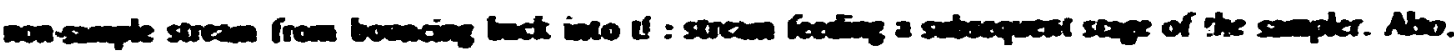

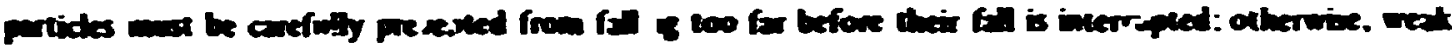

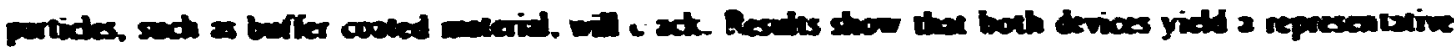

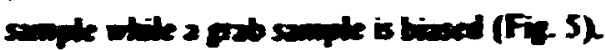

\section{Pride Toras}

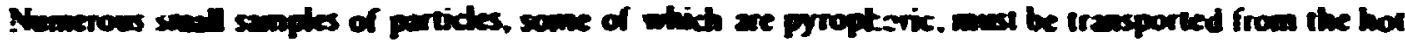

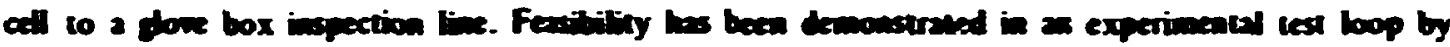

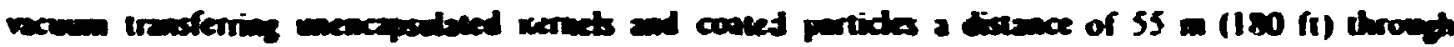

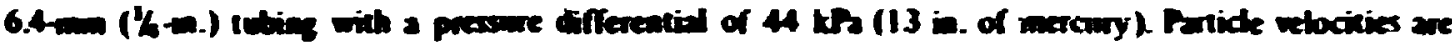

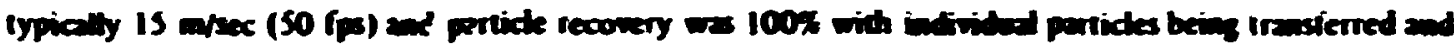

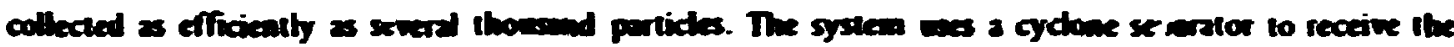

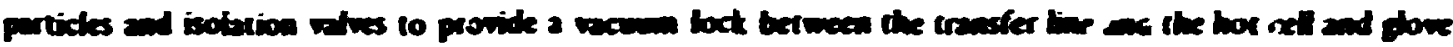
box anosipheres.

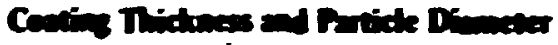

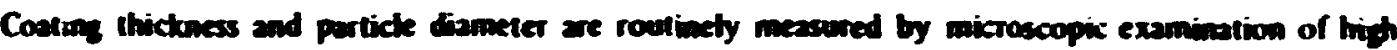

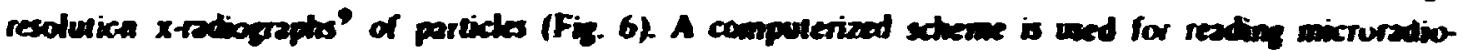
praphs. The dital oatpos from a fitor eyepiece is imbediatedy procesed and printed by a sanell compunet. tatividuel values. averages, standard deviations and other statistics are obtained for various costing thicknesces and partide dianeters at differeat seaps of conting.

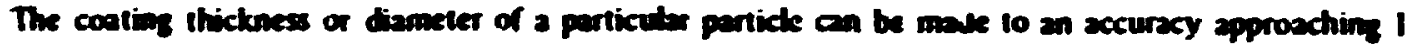
Mm. However, the perticketo-particte variation in coating thirtness and disweter caves a larger uncertainty 10 be anociated with like avera values which characteriae a particle betch. For example. if the standard deviation for the perticle disaneter distribution is $30 \mathrm{~mm}$, then the $95 \%$ confidence interval for the meen of So diameter measurements will be $t 8.5 \mathrm{~mm}$. The uncer!ainty is still $\$ 4.3 \mathrm{~mm}$ for $200 \mathrm{~m}$ messurements.

More precise and rapid particle diameter measurements can be obtained with a particle sice anabyzer which has been developed over the past severd years and is in routine operation. In addition to measuring diameter the andyzer cousts the number of particla per unit mas. This is useful in characteriaing several prticle parameters as well as for material accountability. This device is expecied to be the major source of

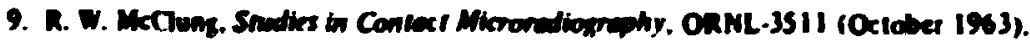




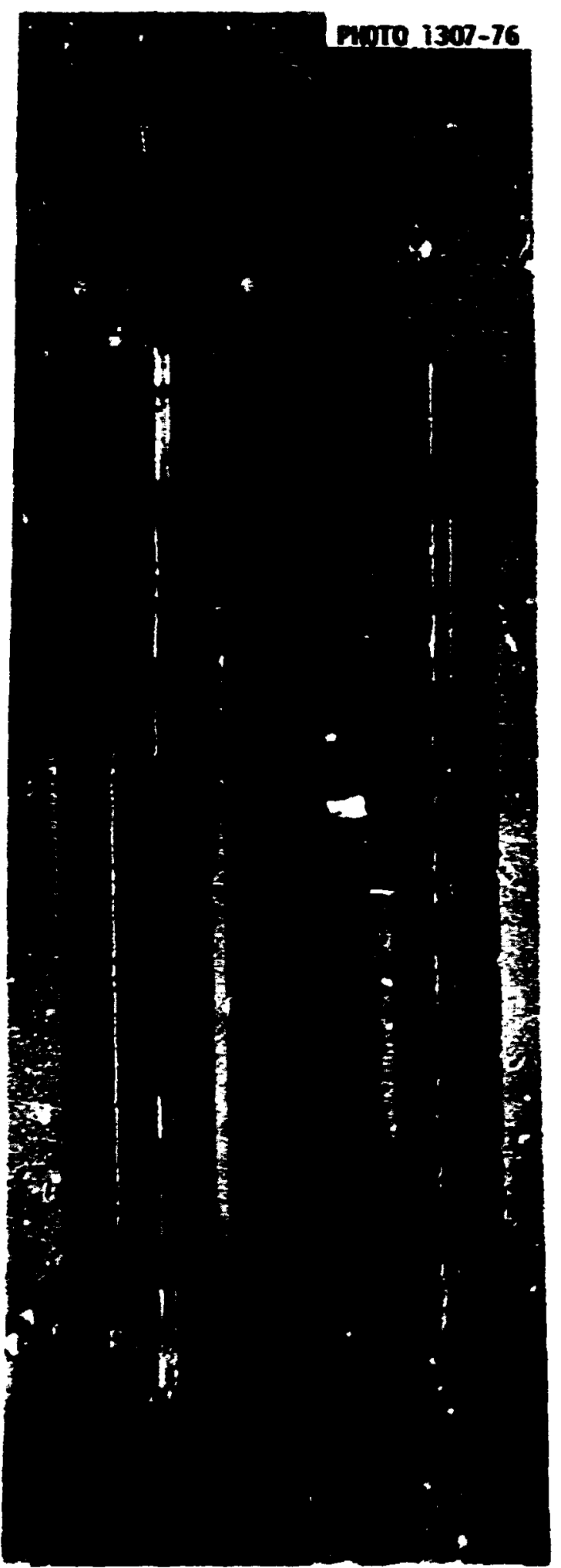

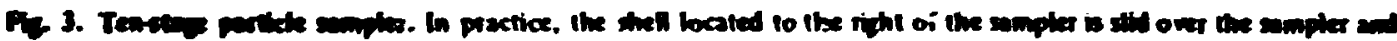

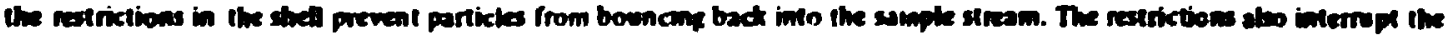

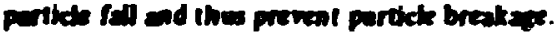




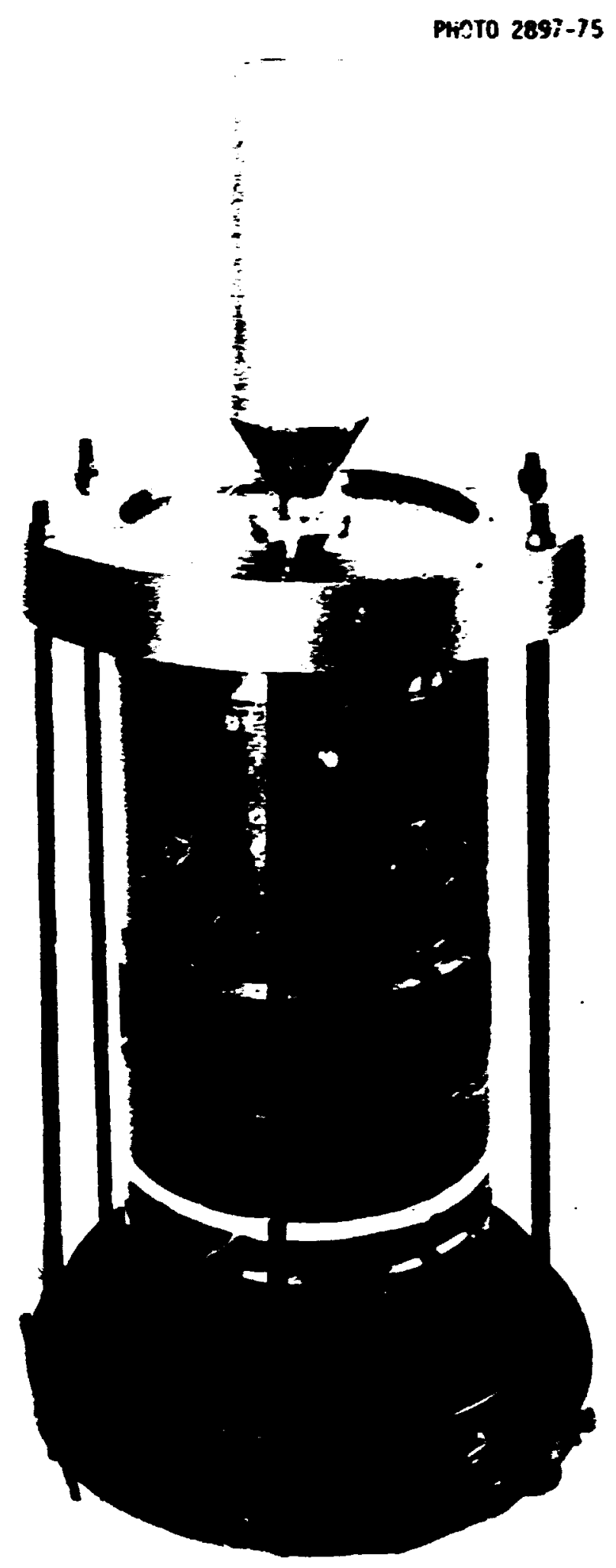

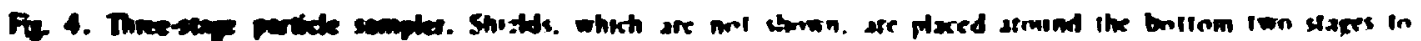

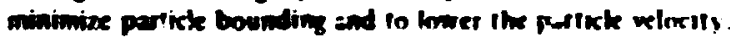




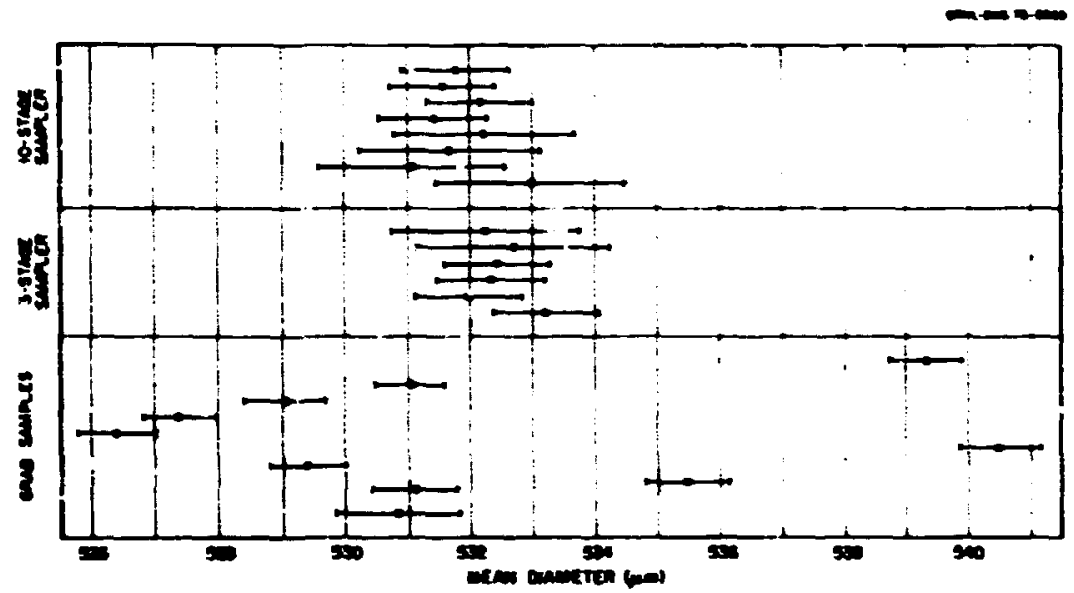

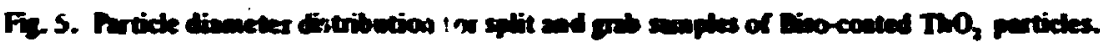

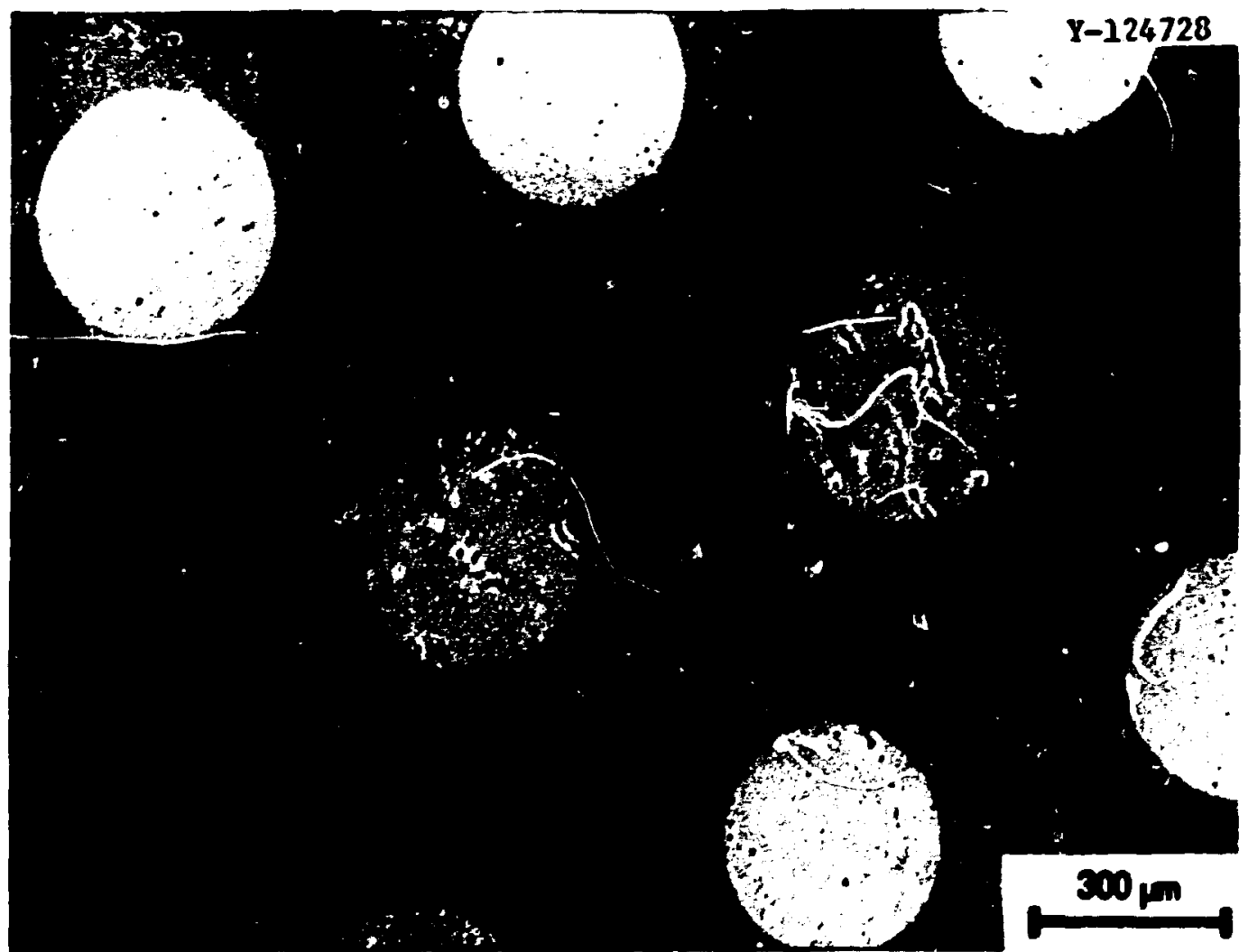

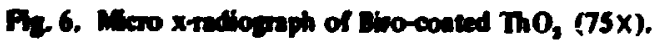

process control data for particle coating operations of future refabrication plaat: The unit (Fig. 7) operates wing the light biockage principle; that is, as a particle passes througl a light beam its shadow causes a recrease in the current output of a photodiode proportional to the cross-sectional area of the particie.

A Schottky barrier photodiode is used as the light detector, receiving a parallel homogeneous light beam from a high intensity lightemitting diode (IED). The LED is Incated at the foral point of a 1 -cm-focallength converging lens which provides a uniform light lield across the face of the photodinde. After signal conditioning which includes analog-to-digital conversion the signal is recorded in one of 1024 channels of a 


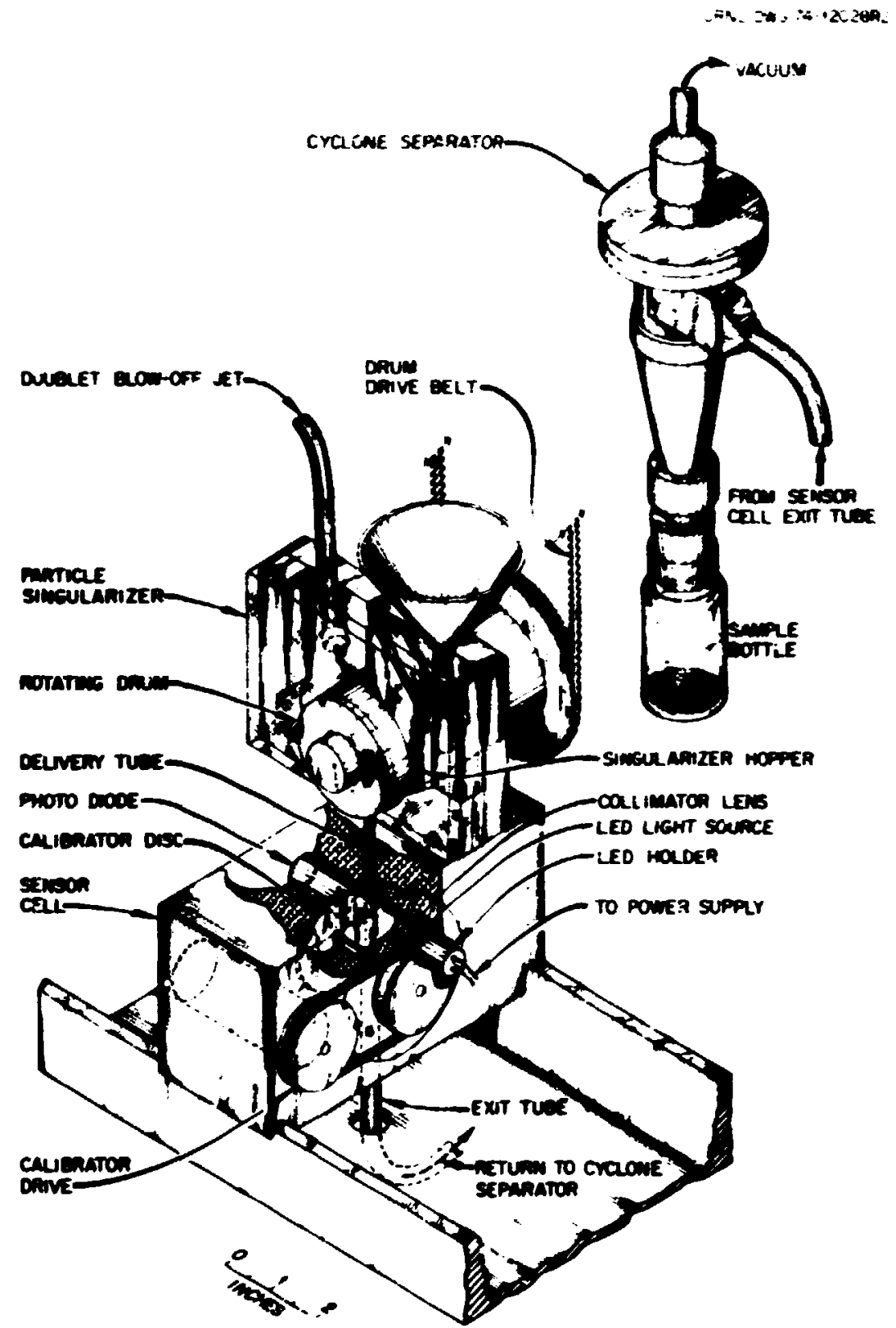

Fi. 7. Turicle size andyzer.

pulse height analyzer. An important component is ti:e particle singularizer (Fig. 7) which ensures that only a single particle is in the light beam at any one time, thus ensuring an accurate count. The singularizer uses a rotating evacuated drum to pick up particles individually on hoies in the drum. As each hole reaches the proper position with respect to the analyzer delivery tube, an air jet positioned inside the drum dislodges the particle from the hole and drives it into the delivery tube. Particles can be measured at a rate of 1500 per 'nin.

The particle size analyzer is calibrated $i$ ii less than 5 min with a set of high-precision steel spheres of four sizes ranging from $\mathbf{3 8 0}$ to $800 \mu \mathrm{m}$. A secondary calibration standard fermits upgrading the calibration cirves between sample runs. Six wires of different diameters protrude radially from a disk hub and 
interrupts the light beam, creating pulses similar to thuse made by the coated partictes. With this secondary sundard a calibration check can be completed in 51010 sec.

Nearly spherical steet mictospheres produce size distributiuns with standard deviations of $<1 \mu \mathrm{m}$ when a single particle is recirculated $\mathbf{2 0 0}$ times. In contrast, the face:ed coated particles characteristically yield standard deviations of 3 to $7 \mathrm{~mm}$ for a single particle recirculated 200 times. Reproducibility of the results obtained with the aralyzer hx been excellent. The $95 \%$ confidence interval about the mean diameter is typically about $2 \mathrm{~mm}$ for a sample of coated particles (Fig. 5). The cuunting efficiency for a clean sample is exentivlly 100\%. These characteristics along with the fast tumaround time have made the particle size analyzer velubble fox puse in coated particle equipment and process development. An erample of the utility of the particte size andyzer is the particte diameter distributions of Fig. 5.

\section{Generel Equations for Costine Dessiny}

Early work in measuring buffer and LTI cuating densities centered around use of three primary piece: of information. These are: (1) the total coating weight. (2) the particle density after coating, and (3) the partick diameter and kernel diameter. Cooting weight is measured by burning the carbon of the kernel; particle denaity is measured by mercury pycnometry; and particie and kernel diameters are determined by high resolution $x$-radiography of a sample of 50 particles. Any two of the three primary pieces of information may be used to calculate coating density; thus three combinations or equations exist. These three equations for cakulating the density of the nth coating are easily derived by performing mass and volume balances and are as follows:

from particle density and burnoff,

$$
p_{1}=\frac{W-W^{\prime}}{(W+1) / p_{p}-(W+1) / \rho_{p}^{\prime}}
$$

from burnoff and radiograpli,

$$
p_{2}=\frac{\rho_{K}(W-W)}{V-V^{\prime}}
$$

and from particle density and radiograph,

$$
\rho_{3}=\frac{\rho_{P}(V+1)-\rho_{p}^{\prime}(V+1)}{V . V}
$$

where

$$
\begin{aligned}
\rho_{1}, \rho_{2}, \rho_{3} & =\text { coating density, } g / \mathrm{cm}^{3} \\
\rho_{K} & =\text { kernel density, } g / \mathrm{cm}^{3} \\
\rho_{P} & =\text { particle density, } g / \mathrm{cm}^{3}
\end{aligned}
$$




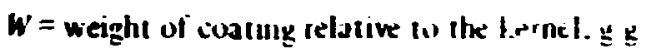

$$
\begin{aligned}
& V=\text { volume of coating relative to the kernel. } \mathrm{cm}^{3} \mathrm{~cm}^{3}
\end{aligned}
$$

Primed quantities are values beticre the inding run: unpumed quantities art values after the run.

The value of $V$ is determined iron radiographic measurentents of the dameter of the particle $\left(D_{P}\right)$ and kernel $\left(D_{K}\right)$. By calculating the ratio $\left(D_{r} ; l_{K}\right)^{3}$ for each of 50 particles and averaging the ratios. the $V$ is computed using:

$$
V=\left(\frac{D_{p}}{D_{K}}\right)^{3}-1
$$

Experiense has shown that Eyuation (1), which is hased on particle density and bu:noff. is the most precise of the three. The precision of $r$ which appears in the "ther two equations is controiled by the standard deviation of the ratio $D_{P} / D_{K}$ ismong particles if the batich and by the number of particles measured. Equation (2) is not very sensitive Io slatistical variation in the value of $t^{\circ}$ while Ey. (3) is virtualky worthless because of its sensitivity to the variation intierent in 5 .

The first two methods using Eqs. (1) and (2) are cruss illecked by comparing results averaged over a series of buffer coating runs. The accuracy of the radiographic measurements is maintained by calibrating the eyepiece against stage micrometers. The precision of the coating weight as determined by burnoff and the precision of the density determination which is done with a mexury pycnometer are checked by analyses of duplicate samples. Obtaining representative samples hy ireful riffling techniques is of the utmost importance. Usually the average ditference b:tween Juplicate burnoif samples is 0.06\%C. Samples are burned in screen-covered platinurs buars at $900^{\circ} \mathrm{C}$. One important kicy to ubtaining precise and accurate results was the addition of an oxygen purge to the furnace atmosphere to ensure complete cumbustion. A study of the effect of sample size on particle density valives obtained by mercury pycnometry showed that by increasing the sample size from $0.5102 \mathrm{~cm}^{3}$ the relative standard deviation was rediced from 0.4 to $0.1 \%$. The $2 \mathrm{~cm}^{3}$ sample is now routinely used. Also. $1.72 \mathrm{MPa}(250$ psi) mercury is used to fill the neeks formed between adjacent particles but with negligible penctration of the coating.

Equations (I) through (3) are always valid for as deposited huffer coatings and are also valid for LTI coatings where the LTI layer is depusited over a nonpermeable substrate as is the case for the outer LTI layer of particles of the Triso design. However. we have repeatedly ohserved if an LTI cuating is deposited on a buffer-coated substrate. some of the carbon deposited during the LTI coating step infiltrates the open pores of the buffer coating. As a result equations (1) and (2) yicld erroneously high values for the LTI density since some of the carbon detected during the burnoff analysis is located within the burfer layer. The interface between the buffer and LTI layers remains very dis:inct as verified by metallographic observation; thus it is appropriate to assuciate the infiltrated carbon with the buffer rather than the LTI layer. For this reason, the above equations for calculating LTI density are not used if the substrate is, buffer coating or even a so-called "secled" buffer coating. The conventional thin sealer layer (up to $5 \cdot \mu \mathrm{m}$ thick) has heen found to be ineffective in preventing infiltration of the buffer layer during LTI coating and use of the sealer has been stopped. Infiltration alters the density and open pore volume of the buffer coating compared to the as-Jeposited buffer coating prior to deposition of the I.TI Jayer. Therefore I wo values for buffer density are usually reported. One value is for the buffer prior in LTI deposition. The second valie is the buffer density after LTI deposition and is obtained by dividing the mass of the as deposited butfer plus the mass of carbon which infiltrated the buffer by the volume of the as-deposited buffer layer. Details of the methods for calculating both buffer density values are presented below. 


\section{As-Deposited Dafier Cooting Dessidy}

Equation (1) is currently best for accurately calculating the density of as-deposited bufter coatings, ie. the buffer density before deposition of the LTI layer. Whes the coating densities for 12 different buffer coating runs were each analyzed in duplicate exing Eq. (1), the average difference in the duplicate values was only $0.007 \mathrm{~g} / \mathrm{cm}^{3}$ (Table 2). While not as precise, Eq. (2) is abo useful for calculating densities of as-deposited buffer coatings. One method for checking the accuracy of the analytical data is to compare buffer coating densities calculated by the two equations (Table 1). For 31 buffer coating runs compared in thie manner, the absolute difference ketween coating density values obtained with Eqs. (1) and (2) averaged $0.027 \mathrm{~g}_{\mathrm{cm}} \mathrm{cm}^{3}$. If all of the difference is assigned to the radiographic measurement, then this difference would correspond to an error in the particle-to-kemel diameter ratio of $<0.8 \%$. While this is larget than the precisions quoted above for the bumoff and density determinations. it is s:ill sufficiently accurate to give a sood cross check on the data and to improve our confidence in the calculated coating density. Such cross checking of the data is easily computerized and is hifhly recommended.

\section{LTI Conting Descity}

As discussed, Fq. (1) is valid for calculating the geometric (bulk) density of LTI coatings provided the substrate is impermeable. For the LTI coating of Biso-coated particles and the inner LTI of Triso-coated particles the substrate is parmeable; thus, an alternative technique has been developed to obtain the geometric density of the LTI layer. This new technique makes combined use of the LTI layer's open porosity fraction and the coating density obtained by the gradient column ${ }^{10,11}$ or sink-float ${ }^{12}$ techniques. The liquid immersion techniques for measuring the density of LTI coating fragments do not measure

10. G. Ostet and M. Yamamoto, "Density Gradient Techniques," Chem. Rev. 63: 257-68 (1963).

11. D. C. Canada and W. R. Laing, "Use of a Density Gradient Column to Measure the Density of Microspheres," And Chem 39: 691-92 (1967).

12. Manfred Gordon and Iain A. Maciab. "A New Diffusion Gradient Method for Thermad F.xpansim Studies with Application to Polystyrer:s," Trans. Fandoy Soc.. 49: 31 - 39 (1953).

Table 2. Asdepositad beffer conting density veleses csleulated aing Eq. (1) and (2) for 12 beffer costing runs.

\begin{tabular}{|c|c|c|c|c|}
\hline Run & $\begin{array}{l}\text { Buffer density } \\
\text { from Eq. (1) } \\
\text { (e/cms) }\end{array}$ & $\begin{array}{c}\text { Duplicate Measurer snt } \\
\text { using }[(q . \text {. (1) } \\
\left(\mathrm{g} / \mathrm{cm}^{3}\right)\end{array}$ & $\begin{array}{l}\text { Aveiage for } \\
\text { Fq. (1) } \\
\left(\mathrm{g} / \mathrm{cm}^{3}\right)\end{array}$ & $\begin{array}{c}\text { Buffer density } \\
\text { from Eq. (2) } \\
\left(\mathrm{g} / \mathrm{cm}^{3}\right)\end{array}$ \\
\hline$A-273$ & 1.150 & 1.144 & 1.147 & 1.175 \\
\hline$A-275$ & 1.138 & 1.123 & 1.130 & 1.033 \\
\hline A-277 & 1.121 & 1.131 & 1.126 & 1.079 \\
\hline A-278 & 1.133 & 1.132 & 1.133 & 1.111 \\
\hline A-279 & 1.124 & 1.139 & 1.132 & 1.139 \\
\hline$A-280$ & 1.125 & 1.124 & 1.125 & 1.113 \\
\hline$A-281$ & 1.133 & 1.126 & 1.130 & 1.167 \\
\hline$A-282$ & 1.149 & 1.133 & 1.141 & 1.149 \\
\hline$A-283$ & 1.131 & 1.130 & 1.130 & 1.117 \\
\hline A.-284 & 1.135 & 1.140 & 1.138 & 1.106 \\
\hline A-285 & 1.138 & 1.132 & 1.135 & 1.186 \\
\hline A-286 & 1.137 & 1.138 & 1.138 & 1.227 \\
\hline Averages & 1.134 & 1.133 & 1.134 & 1.134 \\
\hline
\end{tabular}


geometric density of the LTI cuating because the liyuid penetrates and fills all open pores This the observed iminersion density $\left(\rho_{o}\right)$ is the ratio of the mass $(m)$ of the LTI fragment divided by the volunce of the fragment excluding the volume of open pores - that is.

$$
P_{0}=m /(V-P V)
$$

where $V$ is the bulk rolume of the costing and $P$ is the fraction of the LTI volume which ix spen pores.

The bulk or geometrin density $\left(P_{c}\right)$ of the LTI coating is defined as the mass of the coating divided by its bulk volume - that is,

$$
P_{C}=m / V \text {. }
$$

Solving Eqs. ( $(5)$ and (6) for $m$ and equating them yields the corrected immersion density (geometric density) in terms of the observed immersion density and fraction of open porosity:

$$
P_{C}=P_{O}(1-P) \text {. }
$$

Thus, Eq. (7) can be used to obtain the geometric density of the LTI layer from the observed immersion density provided the pore volume of the LTl layer is known. Fortuna:ely, it is easy enough to measure this pore volume by high pressure mercury pycnometry. For either Biso-coated or Triso-coated particles the difference in densities determined by low and high pressure metcury pycnometry is related to the fraction of the outer coating volume that is open pores.

The mercury pycnometry data is used in the following manner: For a unit mass of particles the bulk particle volume is given by $\frac{1}{p_{L}}$, where $\rho_{L}$ is the particle density as determined by low pressure (1.72 MP2 or 250 psi) metcury pycnometry. Similarly, the particle volume excluding the open pores in the outer coating layer which are filled by high pressure (103 MPz or $15,000 \mathrm{psi})$ mercury is given by $1 / \rho_{H}$, where $\rho_{H}$ is the particle density determined by high pressure mercury pycnometry. The difference in these two particle volumes $\left(1 / \rho_{I}-1 / p_{H}\right)$ is the volume of open pores per unit mass of particles. It follows that multiplying this term by $\rho_{I}$, gives the wiluite of open pores $\left(V_{P}\right)$ per unit volume of particles $\left(\frac{\pi}{6} D_{L}^{3}\right)$ - that is,

$$
\frac{V_{P}}{\pi_{-D_{I}^{3}}}=\rho_{I}\left(1 / \rho_{I}-1 / \rho_{H}\right)
$$

where $D_{l}$ is the diameter of the LTI coated particle.

For a Bisc-coated particle the geometric volume of the particle is equal to the geometric volume of the buffer coated particle plus the geometric volume of the LTl coating - that is,

$$
\frac{\pi}{6} D_{L}^{3}=\frac{\pi}{6} D_{B}^{3}+\frac{\pi}{6}\left(D_{L_{i}^{3}}^{3}-D_{B}^{3}\right)
$$

Where $D_{B}$ is the diameter of the buffer coated particle. 
Solving Eqs. (8) and (9) for $D_{L}^{3}$ and equating yidds riter simplification,

$\frac{V_{P}}{\frac{\pi}{6}\left(D_{L}^{3}-D_{E}^{3}\right)}=\frac{1-\rho_{L} / \rho_{H}}{1-1 /\left(D_{L} / D_{B}\right)^{3}}$.

The left side of Equation (10) is the frection of the volume of the LTI layer which is open pores (P) inos,

$$
P=\frac{1-P_{L} / P_{H}}{1-1 /\left(D_{L} / D_{B}\right)^{3}}
$$

The immarsion density is corrected by determining with Eq. (11) the open porosity fraction of the viluase of the LTI layer and sabstitution this porosity volue into Ey. (7). In prectice the term $\left(D_{L} / D_{B}\right)^{3}$ is oberined by summing the wolume ratios - that is, $\sum_{i=1}^{n}\left(D_{L_{i}} D_{B_{i}}\right)^{3}$. However, simply dividing the average particle diameter by the average dianeter of the buffer coated particle and cubing has been shown by numerous comparions to be sufficiently eccurate. Equation (11) abso applies to the outer LTI layer of a Triso-conted particle, if $D_{L}$ and $D_{B}$ are replaced by the diumeter of the Triso-conted particle and the diameter of the siticon car'side conted particke, respectivily; and density vilues for the fully Triso-coated particle determined by low and hiph presure pycnometry are wed for $\rho_{L}$ and $\rho_{H}$, respectively.

It is important to aote that each analysis used to obtain the data to determine the fraction of open pircaity and the corrected inmersion deraity can be performad with samples of Biso-costed particles. In the case of the outer LTI loyer all that is required is a sample of fully Triso-coated particles. In other words it is not necearary for purpous of obtaining the porosity and corrected immersion density to sample before the application of the LTI lyer. This is en important cossideration for a commercial production operation.

If sempling is doae before application of the LTI layer, as is often done for research and development work, there is a second technique for calculating open poroaity and thus the corrected immersion density. The second technique uses Eq. (1) which requires ampling of the substrate, or in the case of fuily Triso conted pauticles, a rifled portion of particles is bumed beck to the SiC layer. Two LTI conting density vives are calculated by subatituting for $p_{p}$ in Eq. (1) the particle density determined at low pressure and at high pressure, respectively. The ratio of the two calculated coating density values yields the fraction of the LTI loyer which is open poraity:

$$
P=1-P_{1(1.72 \mathrm{MP})} / P_{1}(103 \mathrm{Mrr})
$$

Where $p_{1}(1.72 \mathrm{MPa})$ is the LTI coating density calculated from Eq. (1) using the low pressure value for particle density, and $\rho_{1}(103 \mathrm{MPa})$ is the LTI coating density calculated from Eq. (1) using the high pressure value for particle density.

Equation (12) is exact even when infiltration of the substrate occurs since the errors in $P_{1}(1.72 \mathrm{MPa}$ ) and $\rho_{1}(103 \mathrm{MPs})$ caused by infiltration exactly cancel in the ratio. The frection porosity from Eq. (12) is uned to determine the corrected gradient density from Eq. (7). 
These methods for calculating the geometric densitiss of LTI coatings were validated by the fullowing experiment. Different LTI coating runs were made using impermeable ThO: kernels as the substrate. The LTI density for each coating run was measured using several difierent techniques and compared. Since the substrate was impermeable Eq. (1) was used directly to very accurateiy obtain the geometric LTI layer density, and $b$. th :nethods for curreting the immersion density value were also applicable (Table 3). Values in the third column were calculatec using Eq. (1) and are the most precise measure of the genmetric dersity of the LTI layer. The fourth column was also obtained using Eq. (1! and a particle density value determined by high pressure mercury pycnometry. The resulting calculated coating density agrees with the observed immersion density values of column 2. This agreement is important sipse the comparison is an independent check on the accuracy and precision of the measurement of particle and kemel density. carbon content. and immersion density. The fifth and sixth columns give the fraction of the LTI volume which is open pores calculated using Eqs. (11) and (12), respectively. Colunns 7 and 8 give the corrected immersion density obtained froril Eq. (7) when used in conjunction with Eqs. (11) and (12), respectively. Values from the two methods of alculating corrected gradient density compare very favorably and are in good agreement with the geometric density values of column 3 . This gives confidence in the procedures for calculating the corrected gradient density.

As can be observed metallographically, the outer portion (up to $10 \mu \mathrm{m}$ ) of an LTI coating is more porous than the remainder of the coating layer since this outer skeleton portion of the coating layer did not get infiltrated as much as would have occurred had the costing operation continued. The thickness of this outer porous region is essentially independent of the total LTI coating thickness and thus the difference in observed and corrected immersion density values is greatest fo: thin LTI coatings (Fig. 8). The observed immetsion density was rather insensitive to a change in LTI deposition rate. whereas the corrected immersion density differed by a laree amount for the two deposition rates (Fig. 8 ). This is an important difference and has been observed repeatedly for other coating procuss variables. Thus, the difference between observed and corrected immersion densiry is not fixed but depends on the details of the coating process. Both density values should be determined since a unique correlation between the two does not exist. Als, the coating thickness, or better. the coating ID and OD should be reported.

Aternative!y, the results of the high pressure nuercury pyenometry analysis can be expresser in terms of the volume of open pores per unit mas of LTI coating: but this method is not recommended since the volume of pores per unit mass of coating can remain relatively constant while coating density, measured by observed and corrected immersion density, can simultaneously vary over a wide range.

\section{Buffer Coating Demsity After Deposition of the Low-Temperature botropic Loyer}

As discussed, carbon infiltrates the buffer coating during deposition of the LTI layer and alters the density and volume avilable to accommodate fission gases and fuel swelling. Consequently iwo methods have been devised to measure the buffer density existing after LTI layer deposition. If sampling is performad both before and after LTI coating, then an equation based on burnoff and mercury density determinations can be used. If sampling is performed only after LTI coating, an alternate equation involving radiographic measurements is used.

First consides the derivation of the equation which does not require radiographic measuremants. A carbon mas balance for the Biso-coated particle equates the total carbon content to the mass of carbon in the as-deposited buffer layer plus the mass of carbon infiltrating the buffer plus the mass of carbon in the LTI layer. The carbon mass balance based on a unit mass of kernel is:

$$
W=W^{\prime}+\Delta \rho\left(W^{\prime} / \rho_{B}^{\prime}\right)+\rho_{C}\left(W-W^{\prime}\right) / \rho_{1} .
$$


Teblo 3. Comparison of LTI conting dendity meseumemont techniques

\begin{tabular}{|c|c|c|c|c|c|c|c|}
\hline Sample & $\begin{array}{l}\text { Obeervod } \\
\text { immersion } \\
\text { donsity } \\
\left(a / \mathrm{cm}^{\prime}\right)\end{array}$ & $\begin{array}{l}\text { Eq. (1) using } \\
\text { morcury pyc- } \\
\text { nometer (1.72 MPa) } \\
\text { and burnoff } \\
\text { (U/cm?) }\end{array}$ & $\begin{array}{l}\text { Eq. (I) using } \\
\text { moscury pys' } \\
\text { nomeler (103 MPa) } \\
\text { and burnoff } \\
\left(\mathrm{d} / \mathrm{cm}^{2}\right)\end{array}$ & $\begin{array}{c}\text { Fraction opm } \\
\text { porosity } \\
\text { from Eq. (11) }\end{array}$ & $\begin{array}{c}\text { Fracliol apon } \\
\text { porosity } \\
\text { from Ka. (12) }\end{array}$ & $\begin{array}{l}\text { Corrected } \\
\text { immorsion } \\
\text { dandily } \\
\text { from Fqs. } \\
\text { (7) and (II) } \\
\left(\mathrm{d} / \mathrm{cm}^{2}\right)\end{array}$ & $\begin{array}{l}\text { Corrocited } \\
\text { immersion } \\
\text { donsily } \\
\text { frum Equ. } \\
\text { (7) and (12) } \\
\left(1 / \mathrm{cm}^{2}\right)\end{array}$ \\
\hline $\begin{array}{l}J-349 \\
J-350 \\
J-351 \\
J-352 \\
J-353 \\
J-354 \\
J-355 \\
J-356 \\
J-357 \\
J-358\end{array}$ & $\begin{array}{l}1.712 \\
1.817 \\
1.502 \\
2.013 \\
1.946 \\
1.720 \\
2.044 \\
1.905 \\
1.528 \\
1.948\end{array}$ & $\begin{array}{l}1.042 \\
1.759 \\
1.441 \\
1.998 \\
1.895 \\
1.649 \\
2.040 \\
1.873 \\
1.583 \\
1.812\end{array}$ & $\begin{array}{l}1.710 \\
1.802 \\
1.491 \\
2.016 \\
1.946 \\
1.726 \\
2.048 \\
1.908 \\
1.627 \\
1.941\end{array}$ & $\begin{array}{l}4.01 \\
2.46 \\
3.42 \\
0.90 \\
2.71 \\
4.55 \\
0.36 \\
1.85 \\
2.74 \\
6.68\end{array}$ & $\begin{array}{l}3.97 \\
2.41 \\
3.38 \\
0.89 \\
254 \\
4.45 \\
0.35 \\
1.83 \\
2.69 \\
6.63\end{array}$ & $\begin{array}{l}1.643 \\
1.772 \\
1.451 \\
1.993 \\
1.493 \\
1.642 \\
2.037 \\
1.870 \\
1.583 \\
1.818\end{array}$ & $\begin{array}{l}1.644 \\
1.773 \\
1.451 \\
1.995 \\
1.895 \\
1.643 \\
2.037 \\
1.870 \\
1.514 \\
1.019\end{array}$ \\
\hline
\end{tabular}




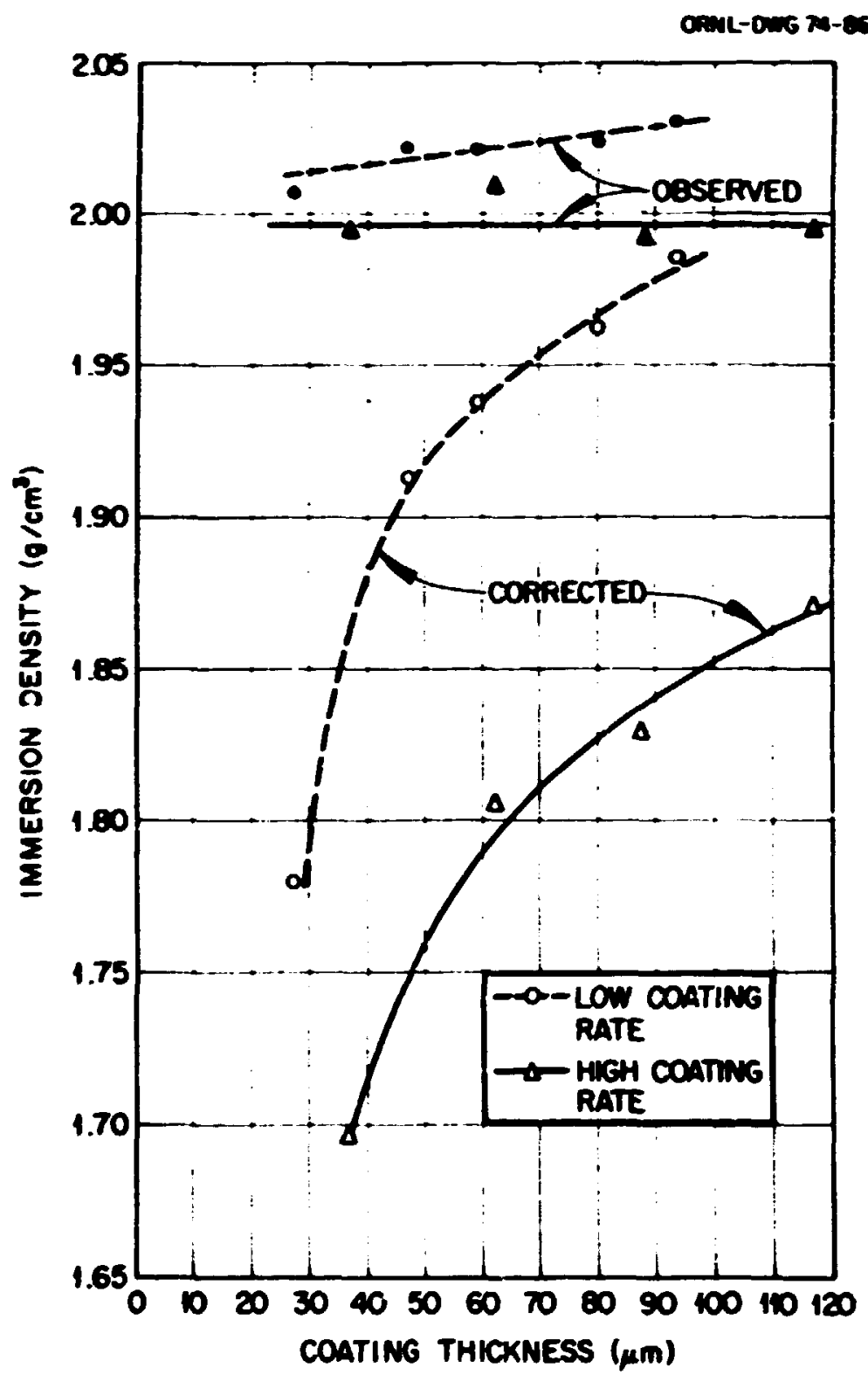

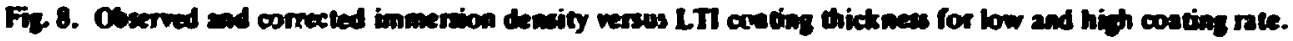

where:

$W$ and $W^{\prime}=$ the mass of carbon coating ;elative to the kernel mass after and before LTI coating, $\mathrm{g} / \mathrm{B}$;

$\Delta \varphi=$ the mass of carbon that infiltrated the buffer layer per unit volume of buffer ccating. $\mathbf{g} / \mathrm{cm}^{\mathbf{3}}$;

$\rho_{B}^{\prime}=$ the buffer density oefore deposition of the LTI layer, $\mathrm{g} / \mathrm{cm}^{3}$ :

$\rho_{C}=$ the LTI layer rorrected immersion density, $\mathrm{g} / \mathrm{cm}^{3}:$ and

$p_{1}=$ the value fur the LTI layer density obtained by using the low pressure particle density from Eq. (1), $\mathrm{g} / \mathrm{cm}^{3}$. 


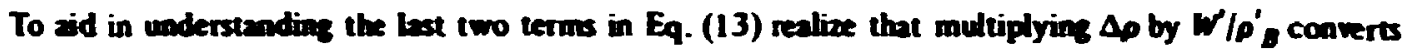
Ap to the basis of mass infiltreted per unit mass of kernel. The factor (W-W Y $\rho_{1}$ is the volume of the LT byer per cait mass of kerned and thus multiplying by the corrected LTI dexcity $6 \mathrm{C}$ ) gives the mass of LT meterial per unit mass of ternel. Solving Eq. (13) for $\Delta p$ gives:

$$
\Delta p=\left(1-\frac{P C}{P_{2}}\right)\left(\frac{w}{W}-1\right) p_{B}
$$

The bufter density after deposition of the LT is now simply obtained by adding the mass infiltrated to the as-deposited buffer density - that is,

$$
\rho_{B}=\rho_{B}^{\prime}+\Delta p
$$

Since only burnoff and mercury pycnometry density determinations are involved Equation (15) accurately yields the buffer density after deposition of the LTI byer. Attention is called to the fact that if the kernel contains carbon then $W$ and $W^{\prime}$ of Eq. (14) are given by

$$
\frac{1}{\left[1 /\left(C_{L}-C_{0} U_{L} i U_{0}\right)\right]-1} \text { and } \frac{1}{\left[1 /\left(C_{B}-C_{0} U_{B} / U_{0}\right)\right]-1}
$$

where

$C_{L}=$ weight fraction carbon in t.e Biso-conted particle,

$C_{0}=w \cdot i g h t$ fraction carton in the kernel,

$U_{L}=$ weight fraction uranium or other actinide in the Biso-coated particle, and

$U_{0}=$ weight fraction uranium or other actinide in the kernel.

The altemate equation for calculating the infiltated buffer density when si.npling is performed only on the Biso-coated particles is derived by performing two mass balances. First, a total mass balance is made followed by a carbon mas balance. The total mass of the particle is equal to the sum of the mases of the kernel, buffer, and LTl coating. The mas of each component is equal to its volume multiplied by its density. Using the symbols defined in Appendix A, the total mass balance is given by:

$$
\frac{\pi}{6} \rho_{L} D_{L}^{3}=\frac{\pi}{6} \rho_{K} D_{K}^{3}+\frac{\pi}{6} \rho_{B}\left(D_{B}^{3}-D_{K}^{3}\right)+\frac{\pi}{6} \rho_{C}\left(D_{L}^{3}-D_{B}^{3}\right)
$$

Simplifyias and solving for $\rho_{B}$ gives:

$$
\rho_{B}=\frac{\rho_{L} D_{L}^{3}-\rho_{C}\left(D_{L}^{3}-D_{B}^{3}\right)-\rho_{K} D_{K}^{3}}{D_{B}^{3}-D_{K}^{3}}
$$

Dividing numerator and denominator by $D_{K}^{3}$ and setting $R_{1}=\left(D_{B} / D_{K}\right)^{3}$ and $R_{2}=\left(D_{L} / D_{K}\right)^{3}$ results in:

$$
\rho_{B}=\frac{\rho_{L} R_{2}-\rho_{C}\left(R_{2}-R_{1}\right)-\rho_{X}}{R_{1}-1}
$$


Equation (18) could be used to celculate the corrected buffer density, but the quantity $\left(R_{2}-R_{1}\right)$ is the difference of the two leas precisely messurable parameters involved and therefore it is desirable to dimiante this quantity. Consider a Biso-coated partick containing a kernel which does not contain arbon. for example, $\mathrm{MC}_{2}$ or $\mathrm{LO}_{2}$. The mass of arbon in the coated particle is equal to the carbon in the buffer plus the carbon in the LTI. Mis carbon balance is given by:

$$
\frac{\pi}{6} f \rho_{L} D_{L}^{3}=\frac{\pi}{6} \rho_{L}\left(D_{E}^{3}-D_{K}^{3}\right)+\frac{\pi}{6} \rho_{C}\left(D_{L}^{3}-D_{B}^{3}\right)
$$

or, after simplifying as before

$$
\rho_{B}=\frac{f_{P_{L}} R_{2}-\rho_{C}\left(R_{2}-R_{1}\right)}{R_{1}-1}
$$

Combining Eqs. (20) and (22) yields:

$$
\rho_{\rho_{L}} R_{2}-\rho_{C}\left(R_{2}-R_{1}\right)=\rho_{L} R_{2}-\rho_{C}\left(R_{2}-R_{i}\right)-\rho_{K}
$$

Solving for $\boldsymbol{R}_{\mathbf{2}}$,

$$
R_{2}=\frac{P_{X}}{\rho_{L}(1-\Omega)}
$$

Substituting Eq. (22) for $R_{2}$ in Eq. (18) and simplifying gives the desired equation for corrected buffer density as follows:

$$
\rho_{B}=\frac{\left\{\rho_{K} /\left[\rho_{L}(1-\Omega]\right\}\left(\rho_{L}-\rho_{C}\right)+\rho_{C} R_{i}-\rho_{K}\right.}{R_{1}-1}
$$

When the kernel contains carbon as well as actinide, $f$ in Eq. (23) is replaced by $f=C_{l}-C_{0} U_{l} / U_{0}$ where the symbols were previously defined.

Figure 9 shows the inzreases observed in buffer density during LTI coating. Note that infiltration depends on the LTI coating conditions: less infiltration was generally observed for higher LTI deposition temperatures.

Before these LTI runs a so-called "sealer" layer 2 um thick had been deposited over the buffer coating. Before application of the sealer the buffer density was about $1.1 \mathrm{~g} / \mathrm{cm}^{3}$. After applying the sealer the density of the composite costing was $1.240 \mathrm{~g} / \mathrm{cm}^{3}$; and thus 1.240 mist be added to each value in Fig. 9 to obtain the density of the buffer after applying the LTI layer. If the sealer had not been applied the values in Fig. 9 would be somewhat larger, but the final buffer densities would be about the same or slightly less. For the most severe infiltration encountered the buffer density increased from $0.67101 .51 \mathrm{~g} / \mathrm{cm}^{3}$ during LTI deposition.

One complicating factor enters into calculating both the corrected gradient density for the LTI caating and the buffer density after application of the LTI when the buffer coated particles are not sampled. 


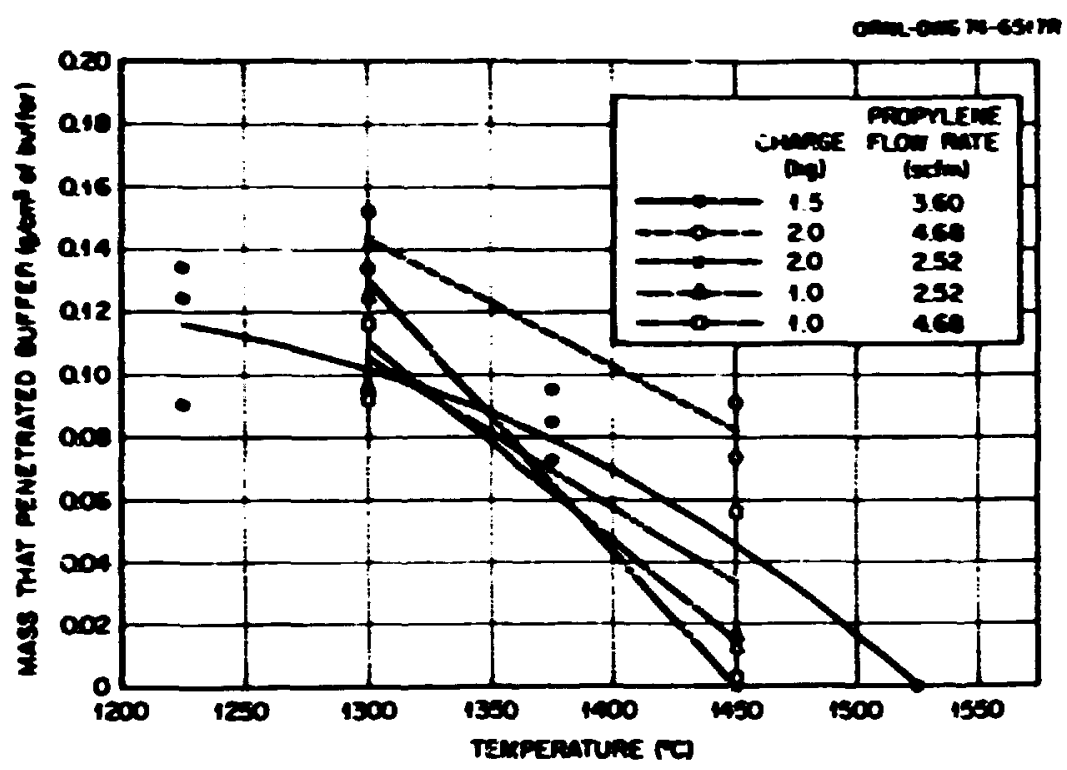

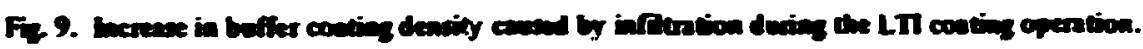

Equations (11) and (23) contain diameter ratios whose measurement requires location of the buffer-LTI interface in an $x$-radiograph of Biss;-coated particles. For Biso-conted particles the apparent location of this interface on a radiograph is ariually several microns inside the true interface (the true interface being defined as the extrtr.ities of the buffer coated particles prior to LTI coating). By comparing the average buffer particle dianeter as determined from a radiograph of buffer coated particles prior to LII coating with the aiziage buffer particle diameter as determined from a radiograph of perticles from the same batch after LTI coating, the error associated with determination of the buffer-LTI interface can be determined. Usually the diameter difference is about $8 \mu \mathrm{m}$ for particles coated using a porous plate gas distributor and somewhat higher for a conical gas distributor. In a limited number of cases where extreme infiltration of the buffer layer occurred the discrepancy in buffer thickness was in excess of $15 \mu \mathrm{m}$. To determine the effect that the uncertainty in locating the buffer LTI interface introduces into the calculations of buffer density anc the corrected immersion density of the LTI, a number of Biso-coating runs were sampled before and after application of the LTI layer. The coating densities obtained with equations not requiring radiograph. measurements were compared with coating densities obtained using equations which did. Results for a small fraction of the comparisons that have been made are given in Table 4.

Colurnn 4 of Table 4 gives the corrected inimersion density for the LTI layer as determined from Eq. (12) which does not require radiogsaphic measurements. The fifth column contains the corrected immersion density for the LII layer calculated without any measurements on the buffer coated particles. Compar. ing Columns 4 and $S$ shows that the error in the latter values caused by the uncertainty in the buffer-LTI interface is small $\left(0.016 \mathrm{~g} / \mathrm{cm}^{3}\right)$. Column six gives the corrected LII coating density from Eq. (11) with the buffer radiograph being used to determine the buffer coated particie diameter. For these valiues the error caused by the difficulty in determining the buffer-LTI interface from Biso-coated particle radiographs is avoided. These values agree closely with the values in column 4, lending validity to the use of Egs. (11) and (12). Similarly, comparisons of buffer density values obtained without radiograph measurements, column 9. with the values of column i0, which were obtained solely from post-LTI data, show that the uncertainty in locating the buffer-LTI interface causes an average error of $20.09 \mathrm{~g} / \mathrm{cm}^{3}$ in the latter values. Actually this error is larger than normally encountentered since this average includes values for several runs having an 


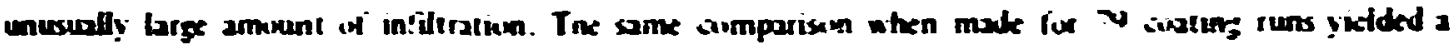

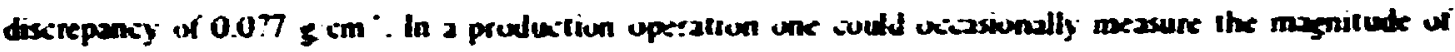

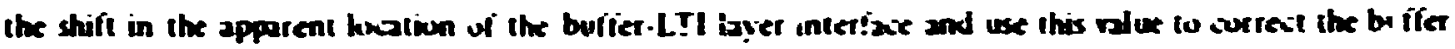
dameter as read frum the Bive ractigyaph. Suth a bufier diameter curretion cuuld signitiantly reduce the uncertainty in the cabulated buffer density. Suh a curreition is usually mode (last calumn of Table +1 . The average difierense between these vilues and $\therefore$ - values of column $\varphi$ is unly $0.036 \mathrm{~g}^{\prime} \mathrm{cm}^{3}$ whith is

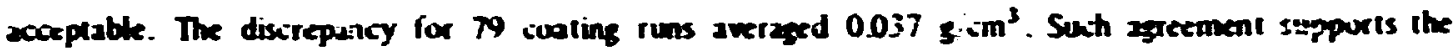
ralidity of with Eq. (15) and (23)

Beatty and Weber'3 are developing a technigee by which the open pre volume of the butier byet is measured by high pressure metcury pycrometry pesformed al ctushed sumples of fully coated partictes. The technique has been demonstntei for partides cuntaining derse tho, kernels and work is in pa toess with puricles contzining porous iesin-derived fissile kernels.

\section{Stricon Cartiele Coation Desidy}

Good quality silicon carbide cuatings are impermeable to liquids: thetefiore the geumelric density of the SiC byer an be determined by immersing tean SIC fragments in a gradient density solumn. The liyuid culumn is prepared from two liquids dijudu methane ar.d a mixture of tetrabrimocthane and benzene. Before immersion the fragments are heated $10900^{\circ} \mathrm{C}$ in oxysen to remove any adhering carbon. The fragments are then treated with $13 . \mathrm{H} \mathrm{HNO}, 0.1 \mathrm{MHF}$ to remuve the $\mathrm{SO}_{2}$ formed during the previous heating; otherwise an erroneously low density value will result. Siliuric asid in the above solution is undasirable since a sulphate residue can often be left on the SiC iragments leading to spurious density values. Before immersion the fragments are dried and then ultrasonicly treated with liquid from the gradient column to wet the fragments. Thoroug; wetting reduces the time required for the fragments to settle to their equilibrium position and impreves the precision.

About 15 fragments are used from a given coating run. Usually the variaticn in densitv from fragmient to fragment is small: the standard deviation is typically $0.005 \mathrm{~g} / \mathrm{cm}^{3}$ and thus the $95 \%$ confidence limit on the mean density for 15 fragments is $+0.003 \mathrm{~g} / \mathrm{cm}^{3}$

\section{Particte Shape}

Most kernel-making processes produce kernels which are essentially spherical and therefore the cuated particle shape is primarily controlied by intraparticie nonuniformity of the carbon coating layers (Figs. 2 and 6). A technique has been developed for quantitatively measuring the shape of coated particles. "4 Firs!. the coating thickness on diametrically opposite sides of the particle is measured by microscopic examination of an x-radiograph as previously described on page 5 . The index of merit. termed "shap: ratio" is obtained by dividing lie coating thickness on one side of a particle by tile thickness on the opposite sidc. The larger thickness is always placed in the numerator, so that the shape ratio is greater than unity. The average value obtained from measurements on 50 to 100 particles is used to characterise a particle batch. The comparison of the shape ratio values with the visual appearance shows that the shape ratio is a meaningful measure of particle shape or faceting (Fig. 10). Further evidence tlat the shape ratio accuiately reflects particle shape is that a correlation was shown to exist between shape tatio and particle packing fraction.

13. Privale communication with R. L. Beally. Oak Ridge National Lahoralory. March, 19/6.

14. W. J. Lackey. W. H. Pechin, and J. D. Sease. "Measurement and Control of Shape of Ivel Particles for Hogh Temperalure Gias-Conled Reactors," Am. Cerom. Soc. Bull. 54: 71824 (August 1975). 


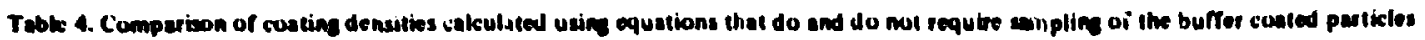

\begin{tabular}{|c|c|c|c|c|c|c|c|c|c|c|c|}
\hline \multirow[b]{2}{*}{ Sumple } & \multirow[b]{2}{*}{$\begin{array}{c}\text { Dascrepandy } \\
\text { in buifier } \\
\text { inichness } \\
\text { (um) }\end{array}$} & \multirow[b]{2}{*}{$\begin{array}{l}\text { A.Tl uhserved } \\
\text { immersiun } \\
\text { dinsily } \\
\left(x / \mathrm{cm}^{3}\right)\end{array}$} & \multicolumn{4}{|c|}{ 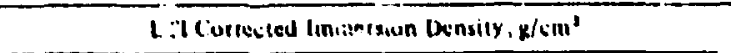 } & \multirow[b]{2}{*}{$\begin{array}{l}\text { Huilut density } \\
\text { befure LTI } \\
\text { depusition } \\
\text { (w/cin') }\end{array}$} & \multicolumn{4}{|c|}{ 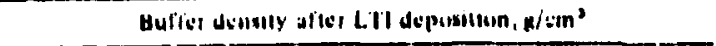 } \\
\hline & & & $\begin{array}{l}\text { Frum } \\
\text { tiq (12) }\end{array}$ & $\begin{array}{l}\text { From liy (II) } \\
\text { using Hiso } \\
\text { Padicypraph }\end{array}$ & 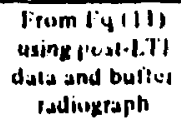 & 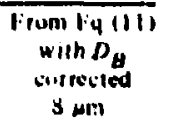 & & $\begin{array}{l}\text { linom } \\
\text { lyty(15) }\end{array}$ & 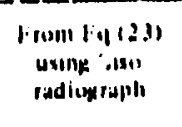 & 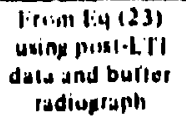 & 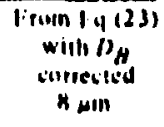 \\
\hline (Cislumn 1) & (Column 2) & (Culumn 3) & (Culumn 4) & (Columis: 5 ) & (Column o) & ('olumn 7$)$ & (Column B) & $($ Culumn 4$)$ & (ciolumn $\mid u)$ & (C) Wumn II) & (Collumin) 12) \\
\hline $\begin{array}{l}3 \text { \$1 } \\
3\end{array}$ & $\begin{array}{r}9 \\
16\end{array}$ & $\begin{array}{l}1.934 \\
1.922\end{array}$ & $\begin{array}{l}1.833 \\
1.828\end{array}$ & $\begin{array}{l}1341 \\
1.838\end{array}$ & $\begin{array}{l}1.839 \\
1.82 x\end{array}$ & $\begin{array}{r}1.837 \\
.834\end{array}$ & $\begin{array}{l}1.106 \\
1.010\end{array}$ & $\begin{array}{l}1.26 .) \\
\left(.14^{\prime}\right)\end{array}$ & $\begin{array}{l}1.183 \\
1.0801\end{array}$ & $\begin{array}{l}1.24: \\
1.178\end{array}$ & $\begin{array}{l}1229 \\
1.134\end{array}$ \\
\hline J- +69 & 12 & 1.966 & 1.819 & 1.824 & 1.813 & 1.818 & 1.14 & 1.315 & 1.269 & $\therefore 330$ & 1310 \\
\hline$A-338$ & 17 & 1.964 & 1.926 & 1.929 & 1.927 & 1.928 & 1240 & 1,337 & 1.236 & 1.287 & 1.240 \\
\hline$A+96$ & 20 & 2.021 & 1.938 & 1.949 & 1.931 & 1.445 & 1.085 & 1.340 & 1.275 & 1.381 & 1,311 \\
\hline A. 498 & 28 & 2.030 & 1.986 & 1.990 & 1.946 & $1,0 \mathrm{ky}$ & 1.085 & 1.323 & 1.239 & 1.363 & $1.2 \mathrm{ks}$ \\
\hline A 499 & 26 & 2.023 & 1.962 & 1.970 & 1.962 & 1.968 & i.uxs & 1.363 & 1.282 & 1.349 & 1.325 \\
\hline$A 500$ & 26 & 1.948 & 1.783 & 1.819 & 1.736 & 1.8112 & i uss & 1.278 & 1.219 & $: 219$ & 1.260 \\
\hline A.5i11 & 21 & 2.021 & 1.912 & 1.930 & 1.913 & 1.923 & i.uns & 1.335 & 1270 & 1.311 & 1.312 \\
\hline$A .18$ & 10 & 1.944 & $1.5+5$ & 1,717 & 1.680 & 1.687 & 1.326 & $1+77$ & $1.4 ! 2$ & 1.494 & $1.4 \times 1$ \\
\hline 1. 530 & 6 & 1.993 & 1.871 & 1.874 & 1.873 & 1.871 & 1.326 & 1.342 & 1.370 & 1.400 & ( ailu \\
\hline A 522 & 14 & 2.009 & 1.80s & 1.415 & 1.797 & 1.804 & 1.126 & 1.375 & 1.124 & 1.402 & 1.369 \\
\hline A 523 & 2 & 1.991 & 1.829 & 1.432 & 1.832 & 1.827 & 1.326 & 1.397 & 1.399 & $1 .+11$ & 1.435 \\
\hline A.525 & 4 & 1.975 & 1.661 & 1.666 & 1.662 & $1.6 \mathrm{J4}$ & $1.30^{\circ}$ & ט. & 1.348 & 1.001 & 1.423 \\
\hline A 593 & 3.1 & 2.040 & 1.906 & 1.940 & 1.905 & 1.934 & 0,670 & 1507 & 1.222 & 1.533 & 1.322 \\
\hline A 604 & 16 & 2.061 & 1.914 & 1.945 & 1.902 & 1.936 & 0.941 & $1: 43$ & I.45s & 1.594 & 1.327 \\
\hline A 606 & 12 & 2.060 & 1.918 & 1.944 & 1.924 & 1.934 & 0.487 & 1.19 & 1.328 & 1.443 & 1.406 \\
\hline A $6 ! 28$ & 14 & 21145 & 1.862 & 1.893 & 1.868 & 1.wo & 1.080 & 1.347 & 1.144 & 1.313 & 1.246 \\
\hline$A 613$ & 11 & 2.053 & 1.857 & 1.887 & 1.851 & 1.871 & $: 040$ & 1.330 & 1.142 & 1.398 & 1.274 \\
\hline Averaper & 16 & 2.003 & J.858 & 1.674 & 1.854 & 1.864 & 1122 & 1.170 & 1.280 & 1.375 & 1.334 \\
\hline
\end{tabular}



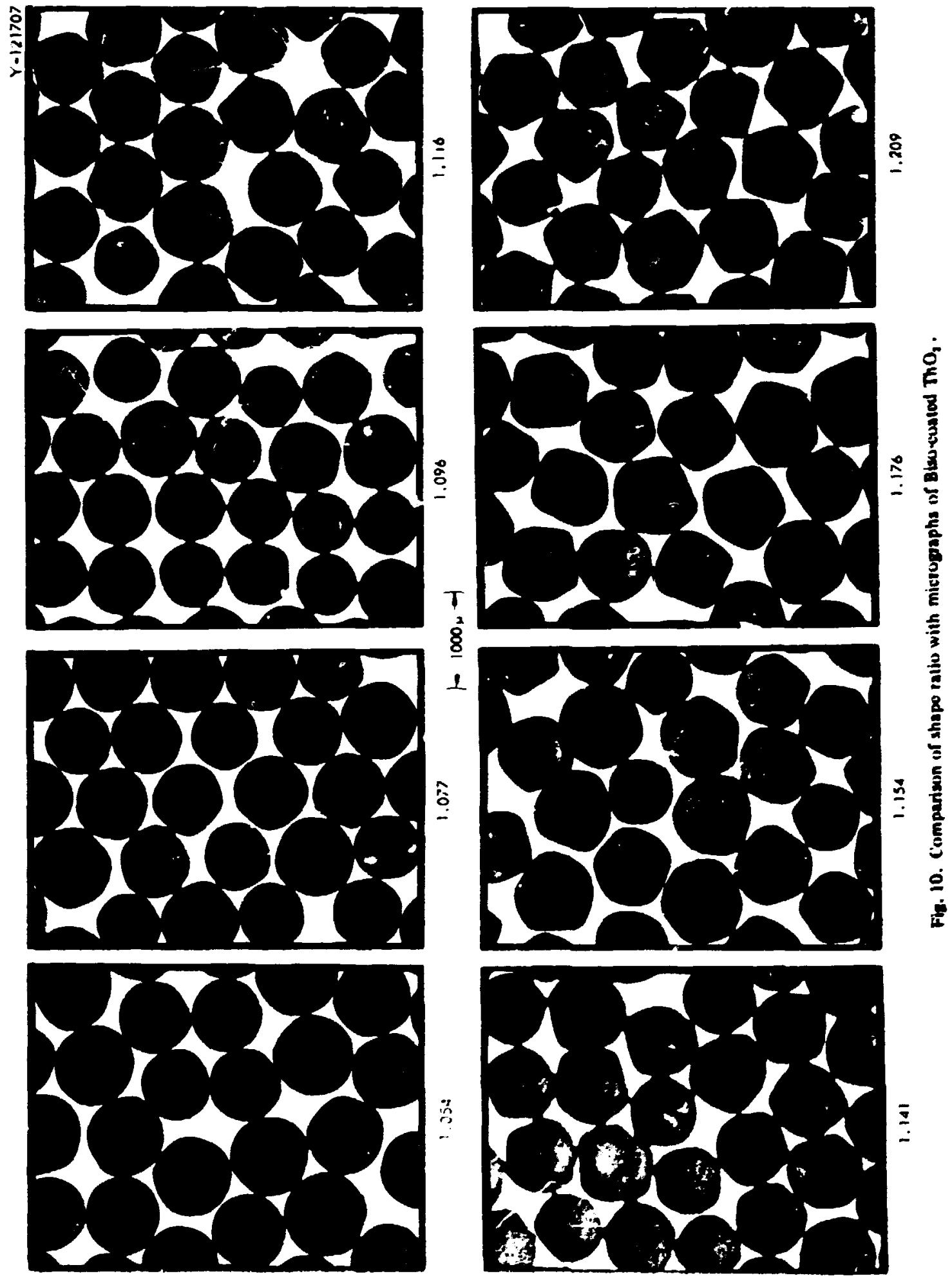
Previous experience in measuring and controlling particle shape ${ }^{14}$ showed that more nearly spherical particles are obtained with smaller furnace changes, greater gas flow rates, and higher deposition rates. Also, a porous plate gas listributur was better than a conical gas distributor.

\section{Particle Surength}

Techniques have been developed for measuring particle and coating strength. 15 - Is A simple test is normally used in which an entire particle is crushed between flat plattens. Results from this test indicates a particle's ability to withstand the forces it is subjected to during pneumatic particle transfer and fuel rod fabrication. Our experience" with messuring crush strength and the influence of coating process variables on strength showed that $1800^{\circ} \mathrm{C}$ postcoating anme al for Biso-coated $\mathrm{ThO}_{2}$ increased particle strength and thus increased the ability of particles to withstand rod fabrication.

\section{Cracked and Permeable Coatings}

Leaching with gaseous chlorine can be used to determine the fraction of Biso-coated particles that have broken or permeable coatings. ${ }^{20}$ The tectnique ${ }^{21}$ uses $1500^{\circ} \mathrm{C}$ gaseous chlorine for $2 \mathrm{hr}$ to remore the exposed leany metals as volatile chlorides which are then quantitatively recovered and analyzed. This technique works for particles containing $T h$ and/or $U$ in the form of oxide and/or carbide. Use of duplicate 10.8 particle samples allows detection of defective fractions of about $10^{-4}$. Figure 11 is an $x$-radiograph of leached Biso-costed $\mathrm{ThO}_{2}$ particles. Note that one kemel has been removed by leaching. The influence of coating thickness and coating process variables on LTI coating permeability has been determined with the aid of the chlorine leach technique. ${ }^{22,23}$ Current emphasis is on correlating chlor. leach results for unirradiated fuel with measurements of fission product release from irradiated specimens.

Measurement of the fraction of defective SiC coatings is more difficult and further technique revelopment is needed. Duming to semove the outer LTI layer (also the inner LTI layer if the SiC byer is cracked), follow ed by aqueous leaching has been used to measure the defective SiC fraction. However, reproducibility of this technique has been poor. An alternate approach ${ }^{24}$ consists of burning followed by pressurization in

15. K. E- Gikchrist and J. E. Brocklehurst, "A Technique for Measuring the Streagth of Hixh Temperature Reactor Fuet Purticle Couting," J. Nod. Mater. 43: 347-50 (1972).

16. K. Dongartz, E., Gyarmati. H. Nicke!. H. Schuster, and W. Winter, "Measurement of Young's Modulus and Fracture Stres on HTR Particte Coatings by the Britle Ring Test," J. Nud Moter. 45 : 261 -264 (1972/73).

17. A. G. Erans, C. Padett, R. W. Davidze, "Strenath of Pyrolytic SiC Contings of Fuet Particles for Hiph-Temperature Cas Cooled Reactors," J. Am. Cenm. Soc. S6: 36-41 (Jankary 1973).

18. P. Krautwaser, H. Nickel, and K. Truber. "Infuence of Mieroporosity on Fracture Siress of Pyrocarbon Coatings," peper C1/3 in 3nd Internetional Conference on Sinuctund Mechanics in Reactor Technolosv, held in London, Sept. 1-S, I975, Vol. 1, Pan C, Comp. by T. A. Jaezer. Commission of the Furopean Communities, Luxembourg. 1975.

19. W. J. Leckey, D. P. Stinton. L. F. Devis, R. L. Beatty, Cnuthing Sirength of HTGR Fuel Particles. ORNL-TM-S I 32 (January 1976). Accepted for publication in Nuckew Technoloxy.

20. P. Koa and H. Bilatein, "Fabrication Methods and Evolotion of U:aniuin-Thorium Carbide Fuel for HighTemperature Gu-Cooled Reactors." in Proceding of the Second Internallond Thorium Fuel Cycle Symposium. Gatlin. burg. Tennesee, May 3-6, 1966, p. 253-272. CONF-660524 (liebruary 1968).

21. D. F. 'ڤValk, D. A. Costanzo. W. J. Lackey, and A. J. Caputo, "The Determination of the Defactive Particle Fraction in HTGR Fuels" ORNLTM-S483 (in-press).

22. W. J. Lactey, J. D. Sease, D. A. Costanzo, and D. F. LaValke. "Improved Coating Process for High-Temperature GarCooted Reector Fuel," Thers. Am. Nuct Soc., 22: 194-9S (November 1975).

23. G. W. Weber, R. L. Beatly, V. I. Tennery, and W. J. Lackey. "The E.ffect of Py rocarbon Coating Permeability on Urandum Redistribution in HTGR Fuels." to be published in Proceedings of Americen Vacuum Sociefy. Inc.

24. D. M. Hewetle. II, and W. K. Laing. "Determination of Defective SiC Layers in Coaled Nuclear Fuel Particles." Nacl. Technol. 21(2): 149-S0 (February 1974). 


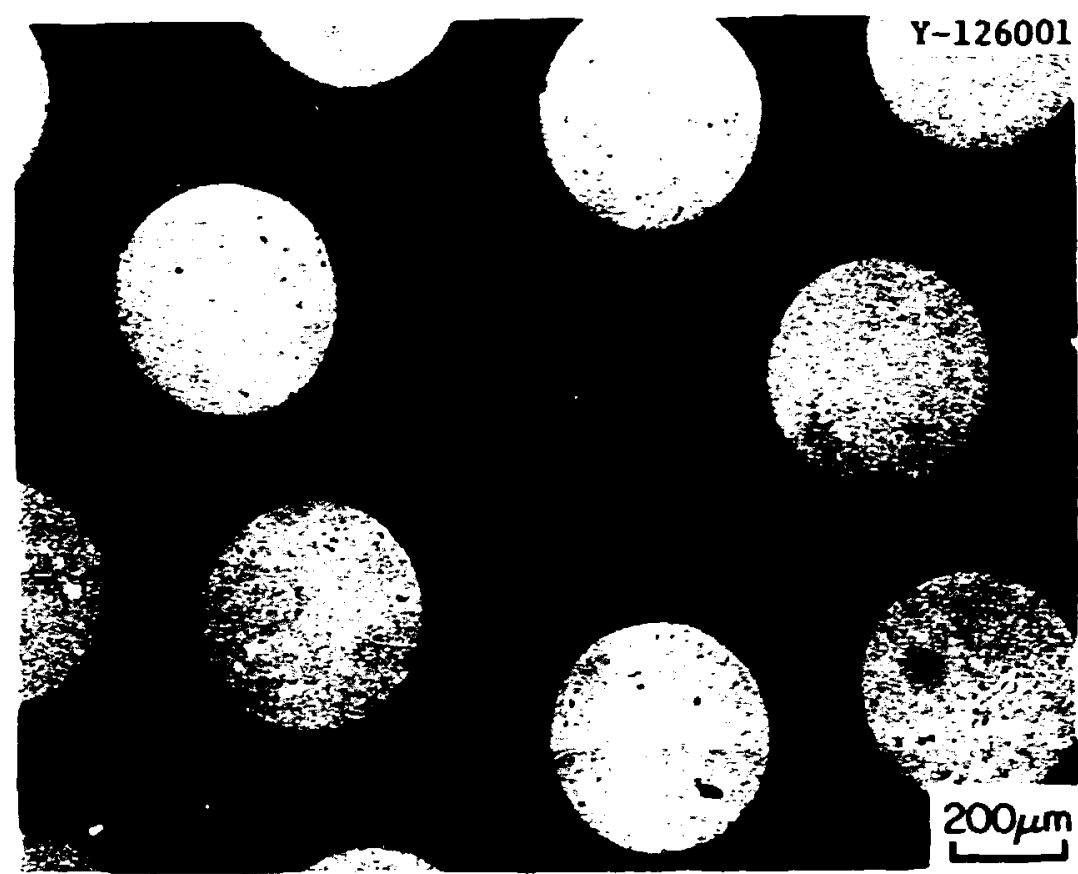

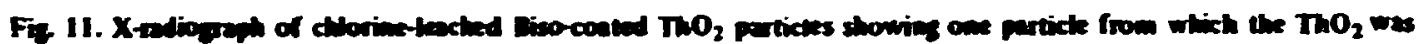
bactived.

$103 \mathrm{MPz}$ (15,000 psi) mercury. The particles are then cleaned of surface mercury and radiographed. Particles having cracked SiC layers will contain mercury and so be recognimable in the radiograph.

No quality control technique, other than visual examination for cracks. exists for the outer LTI layer of Triso-coated particles.

\section{Kernel and Coating Picrostructure}

Conventional iffected light microscupy is of value in characterizing HTGR fuel partides (Fig. 12). Kernels and coatings can be checked for inwanted phases as well as for general integrity. Extensive preferred location of soot inclusion or pors in LTI and SiC coatings can lead to an onion-skin-type structure which may lead to in-reactor failure. The frequency of occurrence of pores in SiC coatings is a check. although not a sensitive one, on the SiC density. Visual observation of the reaction of LTI coatings to polarized light is an indication of the degree of preferred orientation. Polarized light also reveals subsurface pores in $\mathrm{SiC}$.

As research tools. the electron micruprobe and transmission and scanning electron microscopy are useful. Microprobe analysis has been used with resin-derived kernels to show that the uranium concentra. tion is constant from point-10.point within a given kernel and from kernel-10-kernel. II has also been used to show, (Fig. 13) that in some particles there is uranium in the bi fer layer. ${ }^{25}$ Scanniniz cleciron microscopy is useful for examining coating ou:er surfaces and fracture surfaces, particularly for SiC. Transmission

25. G. W. Weber, R. L. Beatty. V. J. Tennery, and W. J. Lackey. "Utanium Dispersion in the Coating of Weak-AcidResin-Derived HTGR Fuel Microspheres." ORNL/TM-S I33 (February 1976 ). 

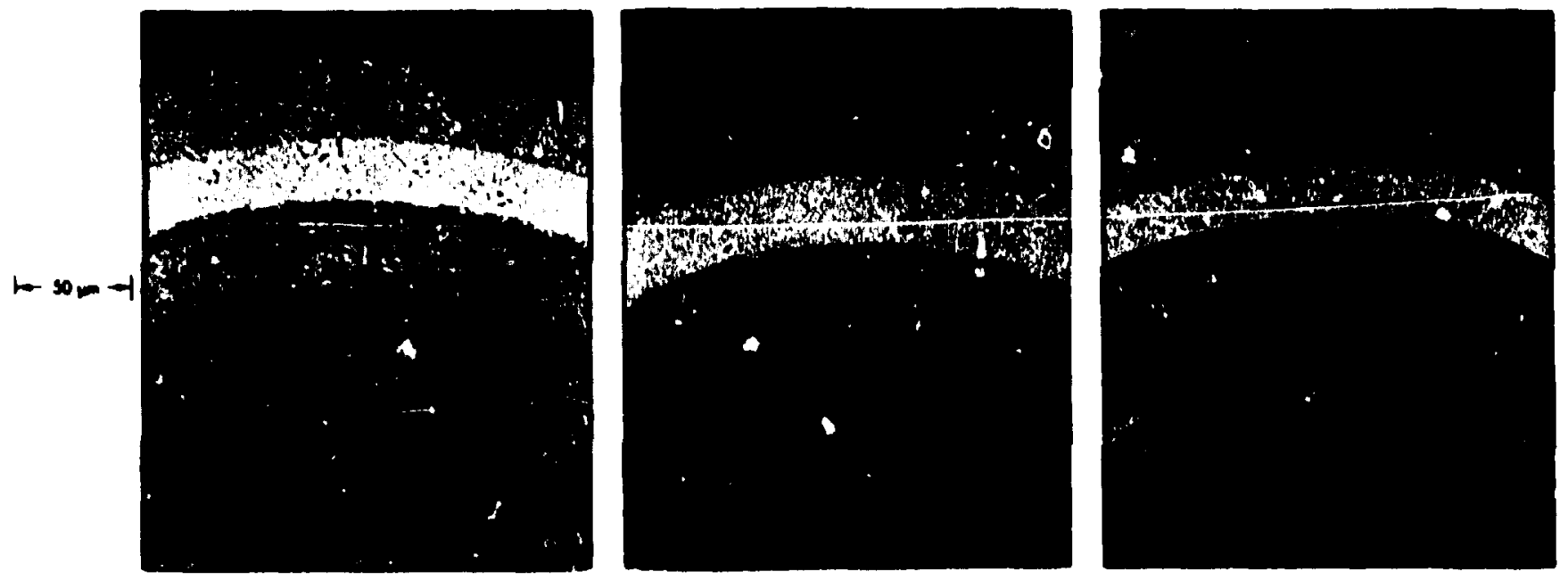

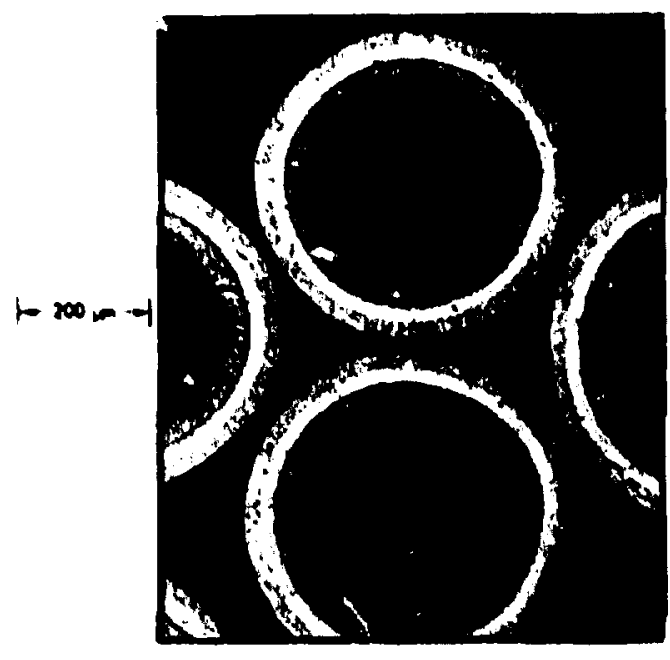

BATCH 1

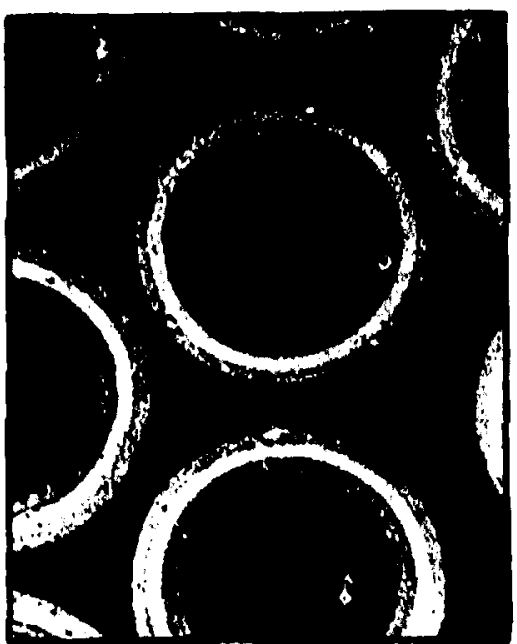

BATCH 2

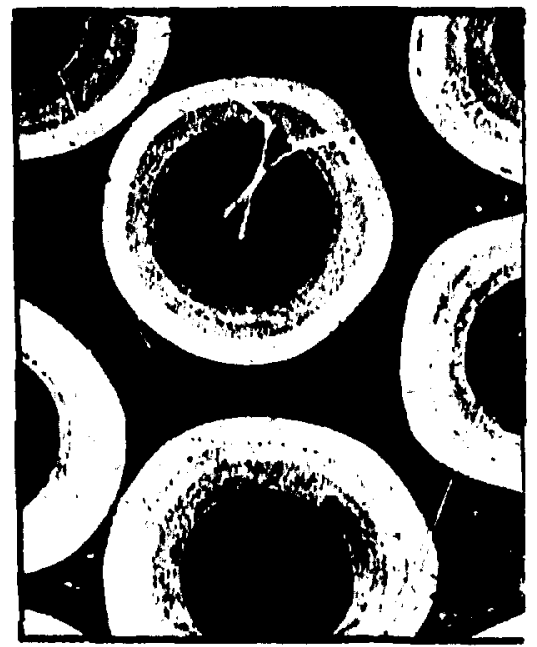

BATCH 3

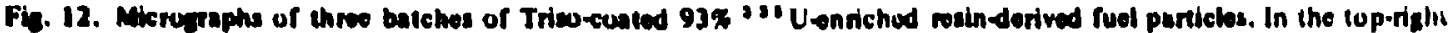
miceograph. pores are visibjo in the SK' layer and a whilo urariturn bearing phace is visible at the kernet-burfor interface. 
electron microscopy " carbon costings 26 - 28 helped in formulating models ior pyrocarbon deposition iend showed that $\mathrm{SiC}^{29}$ coatings are complex and contain numerous stacking faults. Considerable emphasis has been placed on etching of polished LTI coatings by plesma oxidation. ${ }^{30-33}$ This tecthnique yields information which is of some value in predicting coating stability durivy irradiation.

Three methods have been found useful for stching the $\mathrm{SiC}$ coatings. Thermal etching at $1550^{\circ} \mathrm{C}$ for 30 $\mathrm{min}$ in argon has beets successful in revealing the grain struct urr. An electrolytic etchar.t consisting of a mixture of $500 \mathrm{~cm}^{3}$ of $\mathrm{H}_{3} \mathrm{PO}_{4}$ and $2 \mathrm{O}_{8} \mathrm{~K}_{2} \mathrm{Cr}_{2} \mathrm{O}_{7}$ used for $1.5 \mathrm{~m}$ in at a current density of 4 to $5 \mathrm{Aicm}{ }^{2}$ etches both barge and small grained material to reveal the presence of banding or striations. A third etch is involving dipping for 1 to $10 \mathrm{~min}$ in a boiling mixture of equal volumin of saturated $\mathrm{NaOH}$ and $\mathrm{K}_{3} \mathrm{Fe}(\mathrm{CN})$ water solutions etches both large and small grained material but does not show banding as clearly as does the electrolytic etch. The chemicai and thermal etch methods are in close agreement (Fig-14).

\section{reatin Anisotury}

The extent to which the c-axes of the LTI layer crystallites are preferentially aligned perpendicular to the substrate is referred to as ihe Bacon anisotropy factor (BAF) ${ }^{35}$ and is pertinent to irradiation induced shrinkage and coating failure. The BAF value can be determined by $x$-ray diffraction for relatively large disk samples but $x$-ray methods are difficult to apply to microspheres. Therefore an optical technique is employed to measure the anisotropy of LTI coatings on microspheres. ${ }^{36.37}$. More work is needed on any possible influence of coating density on the optically measured BAF value: of annealing and .leposition of SiC on the measured BAF value for the inner LTI: and of sample preparation and equipment detsils on the measured anisotropy value. Aso, more work is needed relating anisotropy to coaling conditions and defining what anisotropy is suitable for the various LTI layers to provide adequate irradiation performance.

iic work has been reported on preferred orientation of SiC crystallites. The influence of this factor as well as other structural features (eg. grain size) on fission product retention needs to be thoroughly evaluated.

26. J. L Kase. T. D. Gulden. and S. Liang. "Transmission F.ectson Microscony of Pyrolytic Carbons Deposited in a Bed of Fuidized Particks." Carton. 10: 701 -709 (1972).

27. J. L. Kaze. "Microsinuctures of Isolropac Pyroly tic Carbons," Corton. 13: 55 - 02 (1975 I.

28. C. S. Yust and H. P. Krautwasser. "Transmisiun Fiketton Miciosciopy of Prappene-Derived Pyrolytic Carbon Coatings." Carbon. 13: 125-133 (1975).

29. T. D. Culden. "Stacking Fauls in Chemkally-Vapor-Deposited Beta Silicon Carbide. " J. Am. Cersm. Sor.. St 498 - 501 (October. 1971 ).

30. H. Luhleich ef al.. "Determination of the Distribution of Amorphous Regions in Pytucarbon Coatings by Means of 'Cold Oxidation,"' Z. And Grem, 225: 97 - 103 (1971).

31. K. Bongartx et al. Jmprosenears in Ovencerizetion of Ayndyfic Drposiled Corton. JUL-1078-RW (June 1974).

32. H. Luhkich et al.. "Improvements in Characterization Methods of Pyrocarbon." pp. 27 - 50 in Qudity Coninol Procedunes on Craphire, Pyrocaron, and Silicon Conbide. Cumpiled by K. Koirlit. GE.RHTR-129. JUL-IIO6-RW ISeplem. ber 1974).

33. 1. P. Mathers. V. J. Tinnery. and E. S. Bumar. Equipment Vatiobles and Deposirion Condirions Affecting the

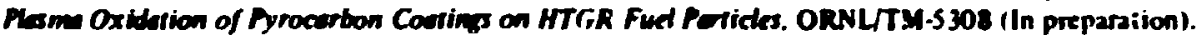

34. Rersonal cnmmunication with J. Holder. C.F..... Grennble. France. April 1979.

35. G. F. Dacon. "A Method for Determining the Degree of Orientation of Ciraphite." J. Appl. Chem. (London). 6 : $477-81$ (1956).

36. Stevens. D. W.. Optical Anisotropy and Preferted Orientation in Nearly isotrmpic Pyrocarbons. GA-AI3307. General Atomic Company. San Diego, Califomiz (January 1975), sub milted for publication in Ceabon.

37. Koizitik. K., Tauber. K., Nickel, H. and Wasmund. H., "On the Influence of the Method of Measurement on the Optical Anisotropy Factor OFTAF of Fy rocarbon," JUL-1082-RW (July 1974): English (ransiation GERHTR-117. 


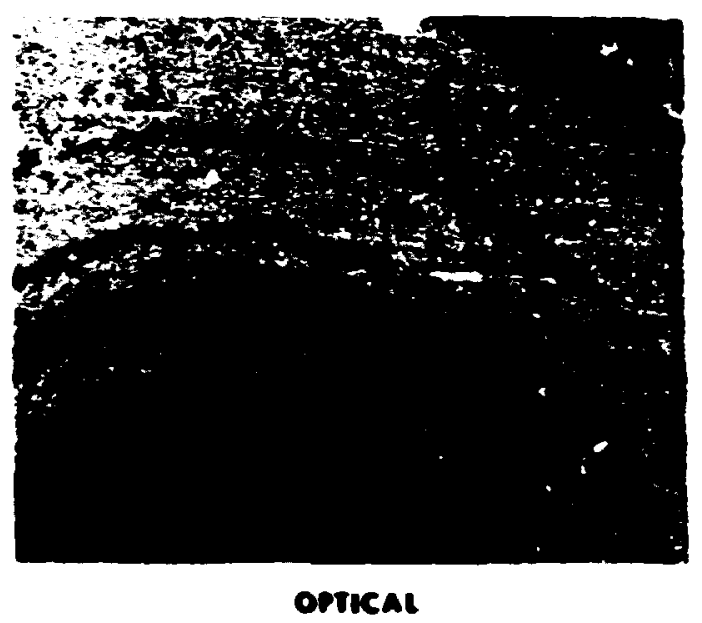

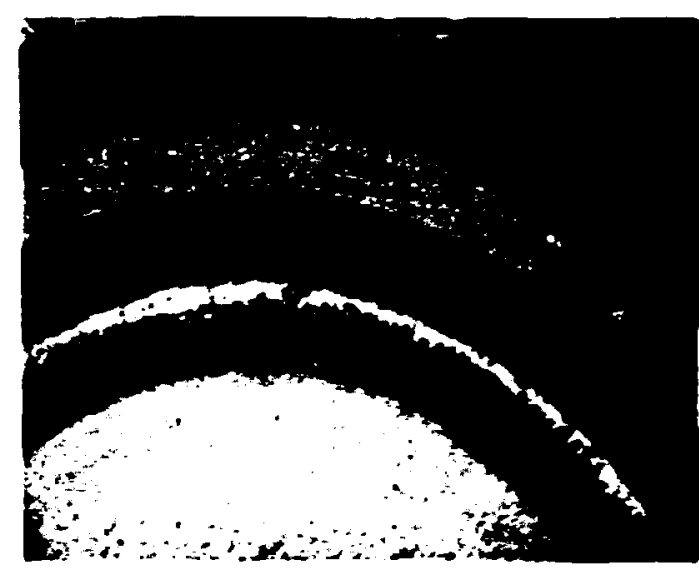

encrscartenco cections

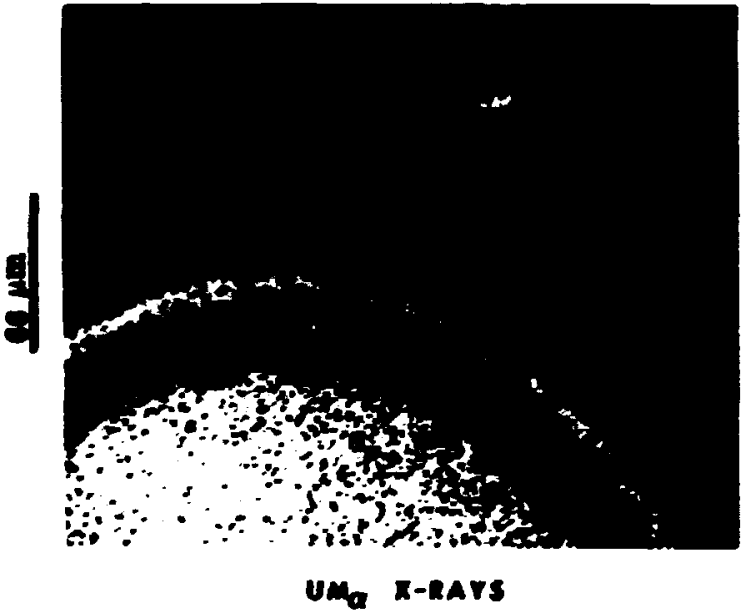

Una r-RATS

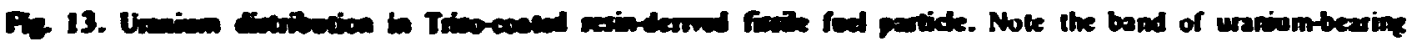

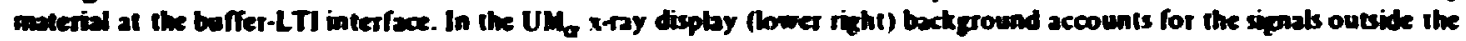
buffer byes.

\section{Urmien, Thorian. and Cerbon Anelysis}

The urenium content of uncoated resin derived faxile kemels is determined gravimetrically by combus. tion in oxyzen to $\mathrm{U}_{3} \mathrm{O}_{\text {. }}$. The carbon content of the kernels is determined by combustion and trapping of the $\mathrm{CO}_{2}$ in acarite. The oxygen content of partially cmverted resin derived kerneis is not as accurately measurable as the uranium and carbon contents and the best oxygen values are oblained by difference. When 32 different batches of carbonized or converted resin kernels were each analyaed in duplicate for uranium and carbon, the average difference in the duplicate analyses was $0.29 \%$ uranium and $0.13 \%$ carbon.

For coated particles, as contrasted to kernels, there is an uncertainty in the uranium content of the sample even for a given number of randomby selected particles, because the kernel size is vatiable (Fig. 15). For example, given a kernel diameter of $260 \mu \mathrm{m}$ and a kernel wolunie standard deviation of $1.87 \times 10^{6} \mu \mathrm{m}^{3}$ (corresponds to a diameter standard deviation of $19 \mathrm{\mu m}$ ) then the uncertainty at the $95 \%$ level of confi- 

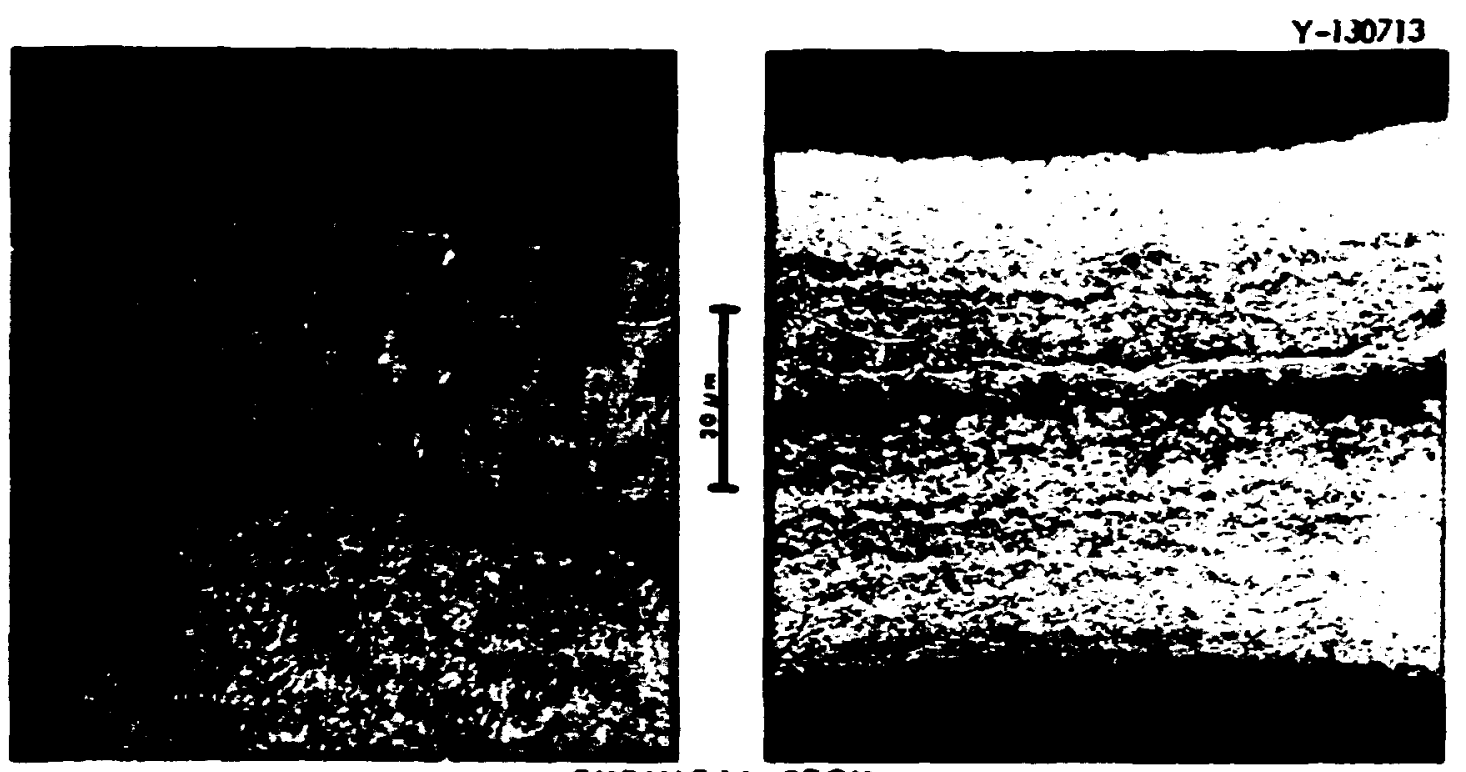

CHEMICAL ETCH

BATCH 1

BATCH 2
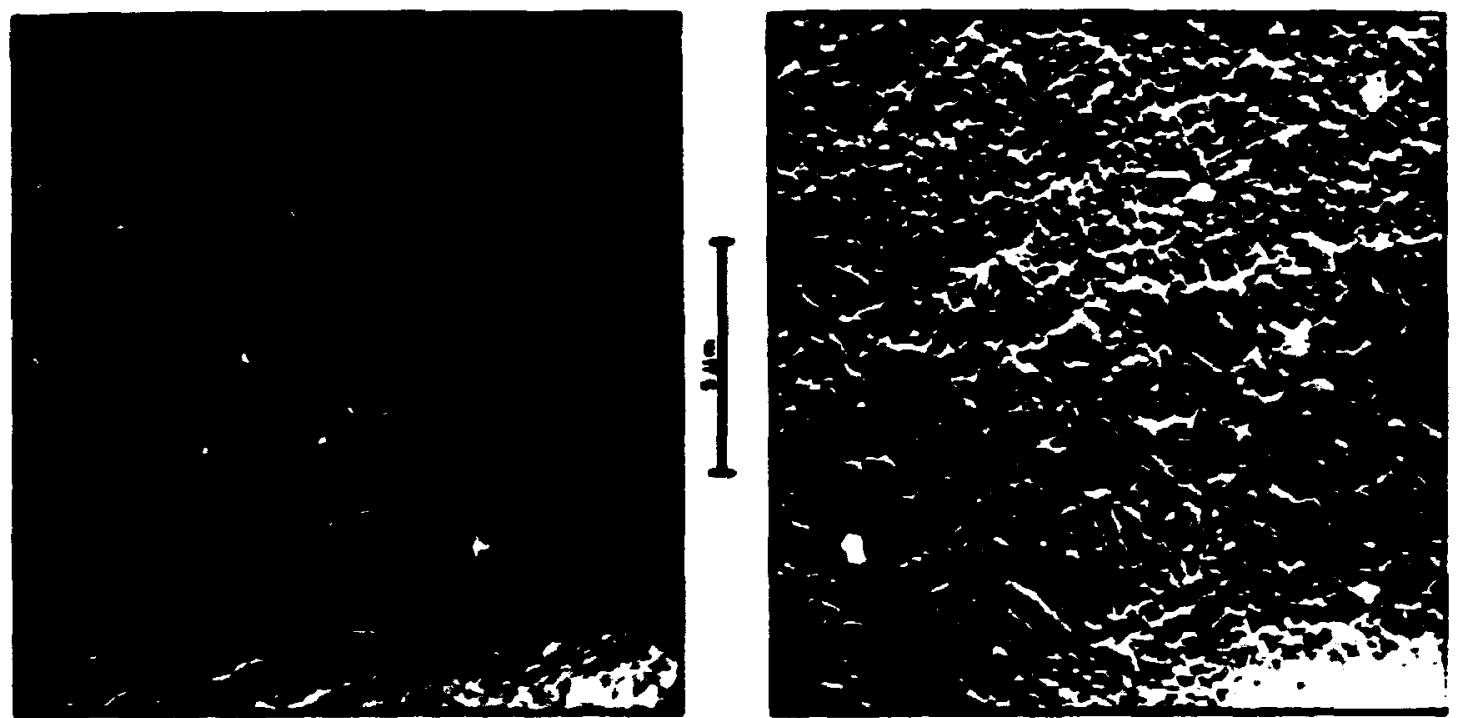

THERMAL ETCH

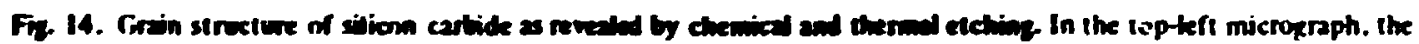
SiC byer and ine underlying layer a CTI zee rivible. The lop-right microgaph shows SiC byers from iwo partickes. The fields of vew for the bottom two nir snataphs are withis the SiC layer.

dence in the uranium con!ent for a sampite consisting of 4825 coated particles $(1.0 \mathrm{~g}$ of Triso-coated parlicles) is $\pm 0.57 \%$ of the uranium coritent. That is, if the actual uranium content of the entire batch were 20\%, then at the 95\% confidence level the uranium content of the sample of coated particles is within the range $20 \pm 0.117$. Rather large samples are required to reduce the selative standard deviation to the $0.1 \%$ value. Actually, on a weight basis the uncertainty is less than shown in Fig. 15 because, since there is no correlation beiween coating thickness and kernel diameter. it follows that there will be a correlation between kernel diameter and coating weight. The larger ketnels tend to have more coating on a weight basis 
and similarly the smaller kemels have less weight of coating on the average. Thus, the uncertainty in uranium content caused by the variation of kernel size is partially compensated. The degree of compensetion was determined by a mathematical analysis which considered not only variations in kernel diameter but also typical particle-to-particle variations in coating thickness for each layer of Triso-coated particle (Table 5).

Compaing these data with Fig. 15 shows that the correlation of kemel diameter with coating weight lowers the uncertainty in the uranium content of samples. but this uncertainty is usually the limiting factor in aclinide analysis of coated particles unless large samples are used.

The thorium content of carbon-canted $\mathrm{ThO}_{2}$ is best determined gravimetrically by burning of the carbon to leave a $\mathrm{ThO}_{2}$ residuc. The precautions necessary to achieve complete combustion mentioned in the section on as-deposited buffer coating density are applicable.

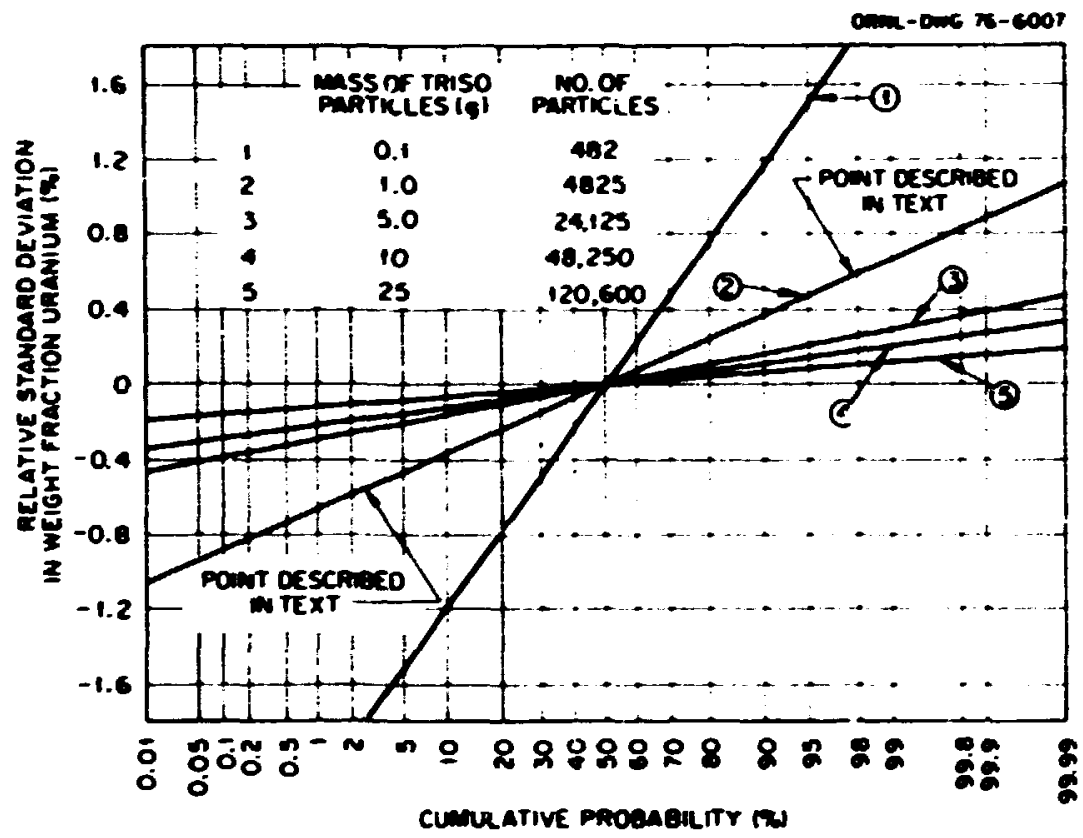

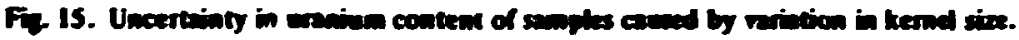

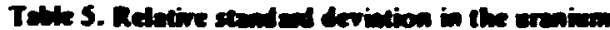

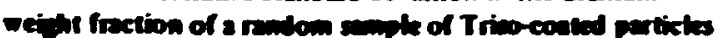
as a fanetion of momble sine

\begin{tabular}{|c|c|c|}
\hline \multicolumn{2}{|c|}{ Sample sine } & \multirow{2}{*}{$\begin{array}{l}\text { Relative standard devialion of } \\
\text { uranisum weight fraction } \\
\text { (x) }\end{array}$} \\
\hline $\begin{array}{c}\text { Weight } \\
\text { (8) }\end{array}$ & Number of particles & \\
\hline 0.1 & 482 & 0.5 .3 \\
\hline 1.0 & 4,825 & 0.163 \\
\hline 5.0 & 24.125 & 0.073 \\
\hline 10.0 & 45,250 & 0.051 \\
\hline IS.0 & 72,400 & 0.042 \\
\hline 25.0 & 120.600 & 0.033 \\
\hline
\end{tabular}


The determination of uranium in Triso-cuated fissile particles is difficult because of the chemically inert SiC coating. Three methods have been used to convert Trisu-coated particle samples to a solution iorm amenable to uranium measurement.

One method involves ignition at $1000^{\circ} \mathrm{C}$ in air to remuve the uuter pyrocarbon layer. fusiori of the intact SiC-oated particles with sodium carbonate. dissolution of the melt in nitric acid. and filiration of the sample solution to remove silica. If carbon is present in the residue, the filter paper and residuz are wet ashed with a mixture of perchloric acid-nitric acid, the solution filtered and the filtrate combined with the bulk sample solution for measurement.

A second method involves crushing the sample, ignition at $1000^{\circ} \mathrm{C}$ to remove the pyrocarbon layers. leaching of the ignition residue with $13 M \mathrm{HNO}_{3}-0.1 \mathrm{MHF}$, and filtration to reinove the insoluble SiC residue. Since a small amount of uranium ( $0.1-0.3 \mathrm{wt} F)$ is associated with the SiC. the SiC residue is fused with $\mathrm{N}_{2} \mathrm{CO}_{3}$ and the melt analyzed for uranium.

A third method involves sequential treatment of the sample with oxygen, chlorine and oxygen at $1000^{\circ} \mathrm{C}$ to remove the pyrocarbon and silicon carbide costings. The oxide residue that remains is then dissolved in nitric acid. This method of sample preparation is quicker than the fusion or grindteach method, $8 \mathrm{hr}$ vs 24-36 hr, respectively. This method is advantageous for giove box and hot-cell operation because the treatment with oxygen and chlorine and the acid dissolution can be performed in a single reaction apparatus.

The precise measurement of uranium in the nitric acid is made by the Davise-Gray method in which the uranium is first reduced with ferrous sulfate and then titrated potentiometrically with dichromate. The relative standard deviation for the precision of this method has been established at 0.05 \%

\section{Impurity Analysis}

Trace impurities in coated particles are best determired iy spark source mass spectrometry. The samples are crushed in a hard-chrome-plated morta: and pestle to prevent the pickup of impurities other than chromium. The crushed sample is mixed with silver powder and pressed into a pellet which serves as the electrnde. Plastic ware is used in the preparation of pellets to further ninimize sample contamination.

\section{FUEL RODS}

Fuel rods 13 or $16 \mathrm{~mm}(1 / 2$ or $\mathrm{s} / \mathrm{h}$ in.) in dianeter and $50 \mathrm{tn} 65 \mathrm{~mm} 122.5 \mathrm{in}$.) long contain mixtures of fissile, fertile and graphite shim parlicles bonded by a matrix of pit th binder and graphite filler. A large HTGR core contains about $9 \times 10^{6}$ rods. The principal activities in the reference recycle fuel rud fabrication pr kess are dispensing. blending. and loading particles into molds: injecling the matrix into a bed of particles Io form a ficl roj: and inspecting. In addition lo describing a system for fuel rod transfer, this section deals with two important rod altributes actinide content and leomogeneity.

\section{Fuel Rod Transfer}

Fired and unfired fuel rods must be transferred oxit of the liot cell to various sample inspection stations. A system las been designed Io load the ronds into capsules. vacium transfet the rods in a receiving station. unload the rnds. and return the sppsules. The method chusen for liading and unloading the rods uses a hollow capsule with "collars" inside carh end for trapping spherical end plugs. A force of unly $4.4 N(1 \mathrm{lb})$ is required to push the resilent ball plugs into and out of the capsule. The capsules were conveyed at about 
$6 \mathrm{~m} / \mathrm{sec}(20 \mathrm{fps}$ ) in $25 \mathrm{~mm}$ diam ( 1 in.) tubing $21 \mathrm{~m}$ ( $70 \mathrm{ft}$ ) long with an air flow of 3.8 std litersisec (8 sefm) at a pressure differential of $1.7 \mathrm{kP}$ (7 in. water). Bends made on $20.46-\mathrm{m}$ (18 in.) radius have posed no problems and $20.0-\mathrm{m}(2 \mathrm{ft})$ dead air column is sufficient cushioning to receive the capsule.

\section{Uhaing Combers}

A nondestructive uranium :-say instrument currently under development for HTGR fued rods will was a ${ }^{252} \mathrm{Cr}$ neutron source to irradiate the uncarbonized fuel lods. The neutrons induce fission in the fissile material, and the resulting prompt fission neutrons are detected with ${ }^{4}$ He-filled proportional counters. The detected count rate is directly related to the fissile content and can be calibrated with rods of known uranium loadings. An advantage of this approach is that the fast neutron detectors can be made insensitive to gamma radiation. The high gamma activity of the recycled fuel precludes the application of many nondestructive assy techniques presently developed for light-water-reactor fivel or ${ }^{235} \mathrm{U}-\mathrm{Th}$ HTCR fuet. The active ${ }^{252} \mathrm{Cf}$ assay method was sefected after a study", 39 of HTGR fuel characteristics and their effect on nondestructive assay techniques.

The assay development program at ORNL is directed towards operation of an engineeringscale assay instrument for ${ }^{233}$ Utoaded fuel rods. The assay instrument must be remutely operatle and maintainable so as to function in-line in a commercial refabrication facility. The program to develop this capability began with the design and fabrication of a laboratory-scale system to optimize the characteristics of a prototypic ascay instrument (Fig. 16). A $1.4-\mathrm{mg}^{252} \mathrm{Cf}$ source is positioned at the center of a cylindrical moderator assembly composed of graphite, poljethylene, and heavy water. The fuel rods are positioned along the periphery of the moderator assembly. In this position they are exposed to well-thermalized neutrons, which selectively fission only the ${ }^{233} \mathrm{U}$ or ${ }^{235} \mathrm{U}$ atoms within the rods. The fission neutron detector which is a

"He proportional counter, records the number of prompt fission neutrons emitted from the sample. The calculated response function of this device has been previously reported. ${ }^{30}$

For the chemical determination of thorium and uranium in a green rod containing fissile and fertile particles, the rod is reflured in pyridine to dissolve the pitch binder, and the particles are separated from insoluble matrix debris by filtration. The sample is then prepared for thorium and uranium measurement, as previously described for fissile particles. The thorium in the solvent has been determined by precipitation as the oxalate and gravimetric measuremer.i as $\mathrm{ThO}_{2}$ : the thorium has also been determined volumetrically by titration with ethylenediaminetetrancetic acid.

For the analysis of a fired fuel rod, the sample is ignited at $1000^{\circ} \mathrm{C}$ and the thoria kernels and silicon carbide coated fissile particles treated in the manner described for fassile particie sample preparation.

\section{Actinide Homozencity}

Sectioning of a fuel rod followed by chemical aralysis is one method for determining whether the actinides are uniformly distributed throughout the rod. However. this technique is time consuming and expensive, particularly for recycle fuel. Consequently, an effort is underway to develop a nondestructive

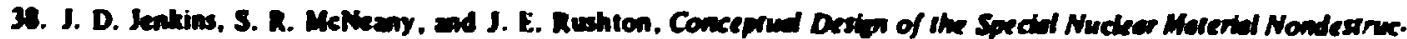

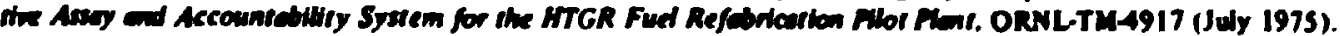

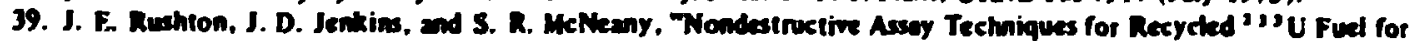

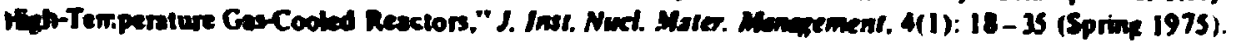




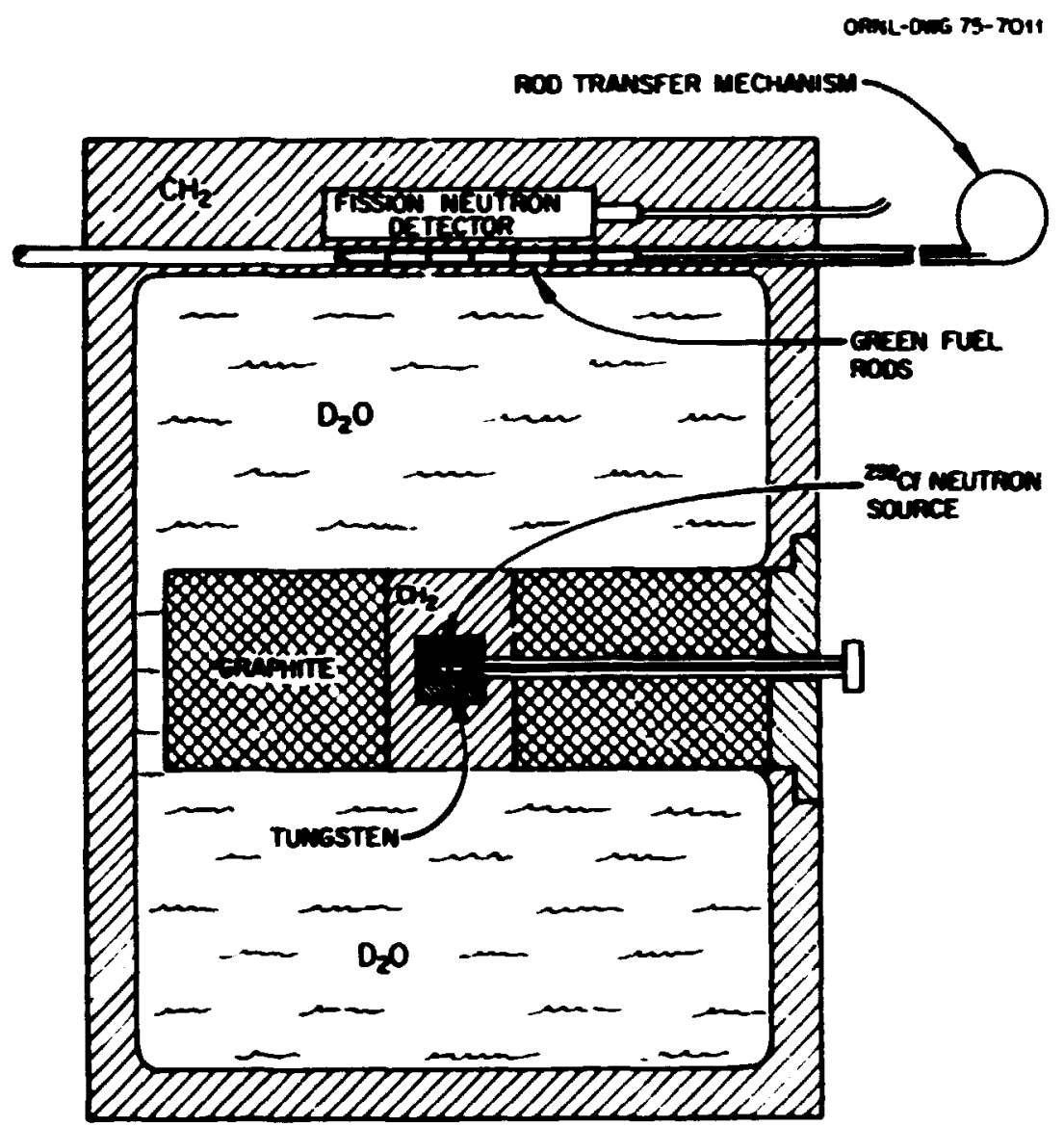

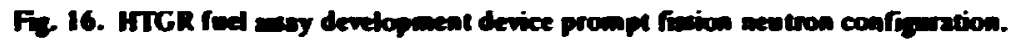

method for measuring fuel rod homogeneity. Approaches wlich have been evaluated are $x$-ray attenuation, gamma-ray altenuation, passive counting of emission from radiuactive isotopes present in fuel rods, nuclear magnetic resonance. and $x$-ray fluorescence. The feasibility of $x$-ray attenuation has been demionstrated for det :mining the axial heavy metal loomogeneity and the possibility of determining radial homogeneity by this method is being studied.

The use of multiple radivisotopes as gamma-ray sources for determining total heavy metal, total mass, uraniuli: thorium, and lighlelement content and relative distribution in fuel rods is being evaluated. A radioisotope source would be advantageous to use in a hot cell environment, since high-voltage power !ires. $x$-ray vacuum tubes, and cooling systems are not required. In addition, the discrete gamma-ray energies simplify the analyses and can yield additional information as in the elemental mass distribution in fuel rods.

\section{FUEL ELEMENTS}

The portion of fucl element fabrication which must be performed remolely consists of the follow. ing: (1) loading of the green (unfired) fucl rnds into the fucl element block. 12 ) lieating the assembly to about $1000^{\circ} \mathrm{C}$ in carbonize the pitch hinder of the rods. (3) annealing at $1800^{\circ} \mathrm{C}$ is) remove residual vovatiles and stabilize fuel rod dimensions. (4) Inading of poison ronds into the element. (5) loading and cementing into place the graphite fuel hote plugs and dowels. and (6) inspecting the fucl elenient. 
Since partivie coatings can crack from the forces present during fuei rod molding, carbonization, and annealing, it is important to measure the fraction of actinide not contained within intact coatings for the final fuel element. Since testing of an entire element is not practical samples processed along with the element must be evaluated. The chlorine leach technique previously described for coated particles has been modified for this purpose. The chlorine passes through a quartz tube supporting a hollow zraphite tube, which holds the inductively heated sample. A nlow of chlorine through the approximately 20\%-porows fuel rod is achieved by packing the rod snugly in the holder with porous carbon particles. Typically a 2 lars treatment at $1500^{\circ} \mathrm{C}$ removes $96 \%$ of the exposed thorium. Additional devetopment is needed since this technique would not detect Triso-coated particles having defective SiC layers provided either the innet or outer LTI layer was : intact.

The pore size distribution of the fuel rod matrix is important for three reasons: An excessive amount of macroporosity ( $\mathrm{SO} \mu \mathrm{m}$ diam) reduces fuel rod integrity. (An allowable range is specified for the amount of microporosity.) Excis microporosity lowers the matrix thermal conductivity while too little microporosity can result in a matrix which is too strong which can lead to tearing of LTI outer coating layers during carbonization, annealing, and irradiation. Matrix pore size distributions are measured on polished rod crosssections using commercially available quantitative image analyzing systems.

Other ived element altributes requiring measurement are pressure drop of coolant passages, surface contamination, and inechanical integrity. Ultrasonic techniques may be suitable for measuring element integrity.

\section{CONCLUSIONS AND RECOMMENDATIONS}

1. High radiation levels require that sample inspection be performed in shielded glove boxes with autoraated sample handiing and analysis zquipment.

2. Means for obtaining and transferring representative particle and rod samples have been developed.

3. Precise methods have been dereloped and demonstrated for measuring buffer coating densily after application of the LTI layer and for measuring the geometric density of LTl coatings.

4. Useful techriques exist for the measurement of particle shape and strength.

5. The chlorinc leach technique is use ful for determining the fraction of defective Bist-inated particles but additional development is needed for Triso-coated particles.

6. Important areas requiring further Jevelopment are coating anisotropy. correlation of SiC properties with fision product release rates, nondestructive assay, measurement of fuel rod homogeneily, and inost fuel element inspections.

7. As a matter of philosopy, inspections performed in support of initial and recycle fuel fabrication development activities and inspection of fuei fabricated for irradiation testing should br: extensive. Practi. cally every prosible characterization teclinique should be used so that a thorough understanding of individual fuel properties and property correlations can be made. On the other haid. a major consideration in development of inspection techniques for future commetcial production operations is that the fabrication piniess should be interrupted as little as possible. Fur example, il is undesirab'e lo interrupt the coating process after the application of each coating layer: the goal in particle charac: rization is to be able tI) adequately characterize particles given opiy a sample of the completely icoted particies. 


\section{APPENDIX A}

\section{SYMBOLS IISED FOR DERIVATION OF EQLATION (23) FOR CALCLLATING BUFFER DENSITY AFTER APPLICATION OF THE LTI LAYER}

$\rho_{\theta}=$ Co-rected density of buffer coating after application of ilhe LTI layer. $/ \mathrm{cm}^{3}$.

$p_{k}=$ Geometric density of kemel, $g / \mathbf{c m}^{3}$.

$f=$ Weight fraction carbon in Biso-coated particle.

$\rho_{L}=$ Geometric density of Biso-costed particles obtained at low pressure meriury. $\mathrm{g}^{/ \mathrm{cm}^{3}}$.

$\rho_{C}=$ Correcied immersion density (geometric density) of LTl coating. $\mathrm{g} / \mathrm{im}^{3}$.

$D_{K}=$ Diameter of kemel. $\mathrm{cm}$.

$D_{B}=$ Diameter of buffer coated particie, im.

$D_{L}=$ Diameter of LTl coated particle, $\mathrm{cm}$.

$R_{1}=$ Average value for $n$ partisles of the ratio of the volume of the buffer coated particle to the kernet volume

$$
=\frac{\sum_{i=1}^{n}\left(D_{B_{i}} / D_{x_{i}}\right)^{3}}{n}
$$

This quantity is given sufficiently eccurately for values of $n=50$ to 200 by cubing the value chtained when the average diameter of the buffer coated particle is divided by the average kernet diameter, that is, $\left(\bar{D}_{B}\left(\bar{D}_{K}\right)^{3}\right.$.

$R_{2}=$ Average value for the ratio of the volume of the LTI cuated particle to the kemel volume for $n$ particles.

$$
=\frac{\sum_{i=1}^{n}\left(D_{l-i} \mid D_{K_{i}}\right)^{3}}{n}
$$

\section{ACKNOWLEDGMENTS}

The authors express !heir thanks to the numeriws people who made this work prossible. In particular. the assistance of R. L. Beatty. D. P. Stinton. C. E. DeVorc. and J. B. Flynn in th: preparation and characterization of coated particles was invaluable. R. R. Suchumet and M. G. Willey are thanked for thi:ir efforts in developing the particle samplers. and J. F. Mack and D. R. Johinson were respunsible for the particle and rod transfer studies. J. E. Rushton did the dose rate calculations. and R. W. Knoll analyzed the influence of varying kernel size and coating thickness on the precision of uranium analyses. J. F. Mack and L. J. Turner played major roles in development of the particle size aralyzer. Many weeks of work was perfnrmed by D. A. Costank\%. J. L. Bntts, L. J. Brady. W. R. Laing. D. F. LaValle, and F. R. Layton in developing and using the anajyical chemistry lechniques. The work dealing with fuel rods was performed by P. Angetini. R. A. Bradley. A. J. Caputo, and D. R. Jorinson. J. D. Jenkins. S. R. McNeany. and J. E. Rushron were roponsible for nendestructive uranium assay. Melallograpliy was performed under like direction of R. J. Giray and B. C. Leslic. The manuscript was edited by (ienge Ciriffith and prepared for publication by the Metals and Ceramics Division Reports Office. 